NBER WORKING PAPER SERIES

\title{
THE INTERNATIONAL DYNAMICS OF R\&D AND INNOVATION IN THE SHORT AND IN THE LONG RUN
}

\author{
Laura Bottazzi \\ Giovanni Peri \\ Working Paper 11524 \\ http://www.nber.org/papers/w11524 \\ NATIONAL BUREAU OF ECONOMIC RESEARCH \\ 1050 Massachusetts Avenue \\ Cambridge, MA 02138 \\ July 2005
}

We thank Mike Wickens and three anonymous referees for extremely helpful suggestions. We also benefitted from comments by Oscar Jorda, Carlo Favero, Massimiliano Marcellino and Luca Sala. Chad Sparber provided very competent advice in the editing of the paper. Peri acknowledges the Institute of Governmental Affairs (IGA) for partially funding this project. Errors are ours. The views expressed herein are those of the author(s) and do not necessarily reflect the views of the National Bureau of Economic Research.

(O2005 by Laura Bottazzi and Giovanni Peri. All rights reserved. Short sections of text, not to exceed two paragraphs, may be quoted without explicit permission provided that full credit, including $\odot$ notice, is given to the source. 
The International Dynamics of R\&D and Innovation in the Short and in the Long Run Laura Bottazzi and Giovanni Peri

NBER Working Paper No. 11524

July 2005

JEL No. O31, F43, C23

\section{ABSTRACT}

In this paper we estimate the dynamic relationship between employment in $R \& D$ and generation of knowledge as measured by patent applications across OECD countries. In several recently developed models, known as 'idea-based' models of growth, the afore mentioned "idea-generating" process is the engine of productivity growth. Moreover, in real business cycle models technological shocks are an important source of fluctuations. Our empirical strategy is able to test whether knowledge spillovers are strong enough to generate sustained endogenous growth and to estimate the quantitative impact of international knowledge on technological innovation of a country in the short and in the long run. We find that a country's stock of knowledge, its R\&D resources and the stock of international knowledge move together in the long run. International knowledge has a very significant impact on innovation. As a consequence, a positive shock to R\&D in the US (the largest world innovator) has a significant positive effect on the innovation of all other countries. Such a shock produces its largest effect on domestic and international innovation after five to ten years from its occurrence.

\author{
Laura Bottazi \\ Universita' L. Bocconi and IGIER \\ via Salasco, 3 \\ Milano 20136 \\ ITALY
}

\author{
Giovanni Peri \\ University of California, Davis \\ Department of Economics \\ One Shields Avenue \\ Davis, CA 95616 \\ and NBER \\ gperi@ucdavis.edu
}




\section{Introduction}

The process of creation of scientific/technological knowledge is extremely important from an economic perspective. In the long run it underlies the phenomenon of technological growth (e.g. in Romer, 1990; Jones, 1995). In the short run randomness in the discovery of new technologies underlies the occurrence of periods of fast productivity growth and other periods of technological slowdown. These may be the cause (together with other shocks) of economic fluctuations of the kind analyzed by the Real Business Cycle literature (e.g. Prescott, 1986; Kydland and Prescott, 1982; Christiano and Eichenbaum, 1992). The process of innovation and what determines it, however, are not very well known and understood. Only during the recent decades have economists made progress in analyzing it from a theoretical and empirical point of view. Models based on endogenous technological innovation (such as Aghion and Howitt, 1992; Grossman and Helpman, 1991) have been developed to explain productivity growth in the aggregate economy. These models helped economists to focus on the central role of innovation as engine of growth for world productivity. At the same time better and more comprehensive data on research and development (R\&D) across countries and on patents and their characteristics (especially for Europe and the US), have become available and have encouraged a large revival in the microeconomic studies of patenting as a window on the process of technological change (see, for an overview, the book by Jaffe and Trajtenberg, 2002). Our contribution in this article is to propose an aggregate dynamic analysis of the knowledge-generating sector that uses state of the art econometric techniques, considers the long and short run behavior of innovation (and its determinants) across countries and uses R\&D and patent data to capture technological innovation. Innovation is treated as the output of a process that uses R\&D resources and existing ideas as inputs. New ideas are measured using international patents originating from OECD countries and we estimate the production of these ideas for the period 1973-1999, allowing for international diffusion of past ideas across countries.

In this article we take a macro approach by aggregating the idea-generating activities across sectors at the country level. We focus, however, on the idea-generating sector only, rather than also looking at the production sector. The importance of the idea-generating sector should grant it special attention, and we focus this study specifically on the R\&D sector for three reasons. First, very little is known on the origin, timing and delays of technological shocks. Our goal is to 
begin opening the black box of Total Factor Productivity (TFP) by understanding the underlying innovation process and its dynamics. The existing empirical studies on $\mathrm{R} \& \mathrm{D}$ and growth are mostly focussed on the long run analysis and capture a reduced-form relationship between R\&D and TFP. For instance the initial contribution of Coe and Helpman (1995) tested the idea that productivity of a country depends on the stock of past accumulated R\&D of the country as well as on that of its trading partners. Since these three variables are non stationary, this implies a long run cointegration relationship between them. As techniques for testing panel cointegration improved in the late 1990s, several papers, after Coe and Helpman (1995), applied tests of panel cointegration and re-estimated the cointegration vector between productivity (measured indirectly as the Solow residual $^{1}$ ), domestic R\&D and international R\&D. Keller (1998), Kao et al. (1999), Funk (2000) and Edmond (2001) all produced estimates of this cointegration relation using OECD countries for the period 1970-1991. They used recently developed tests of panel unit-root (Im et al., 2003) and of panel cointegration (Pedroni, 1999) to analyze the long run relation between R\&D spending and productivity. While ultimately the behavior of TFP is crucial, the novelty of this paper is that it focuses on innovation in order to better understand this one key source of productivity growth.

The second reason to focus on the knowledge-generating sector is that a very important aggregate property of the so called "idea-based" models of growth depends on the dynamic behavior of this sector. Specifically, a key distinction between the first generation of models (the endogenous growth models exemplified in Romer 1990 or Aghion and Howitt 1992) and the second generation of models (the semi-endogenous growth models such as Jones 1995; Kortum 1997 and Segerstrom 1998) is based on the effect of the "scale" of a country's R\&D sector on its creation of technological knowledge. If the level of total $\mathrm{R} \& \mathrm{D}$ resources in a country is positively related to the growth rate of its technological knowledge, once we control for the access to international accumulated knowledge, then such an economy exhibits strong scale effects. Such evidence would be in favor of the endogenous models of growth. On the other hand, if the level of total R\&D resources in a country is positively related to the level of its technological knowledge, still controlling for the access to international accumulated knowledge, then we would be in the presence of weak scale effects. Such relation, in turn, would be corroborating evidence in favor of the semi-endogenous models of growth. Importantly, this property depends only on the effect of R\&D on the creation

\footnotetext{
${ }^{1}$ Using the method pioneered by Solow (1957).
} 
of technological knowledge and can, therefore, be tested by looking at the long run dynamic behavior of R\&D and accumulated knowledge. As both variables turn out to have a non-stationary behavior the above proposition has implications on the cointegration between R\&D resources and the stock of accumulated knowledge. While a previous test to distinguish between endogenous and semi-endogenous models of growth exists (Jones, 1995), it relies on the relationship between R\&D resources and TFP and only uses time-series data for a small number of countries. Our test is based on the impact of a country's R\&D on ideas generated in that country, accounting for the international diffusion of knowledge. Our test, confirming the previous evidence, does not support strong scale effects (and endogenous growth) but only weak effects (and semi-endogenous growth). Even considering, as we do, the production of pure ideas (measured as patents), rather than their embodiment into TFP, knowledge externalities are not strong enough to feed a process in which countries with larger $R \& D$ resources produce ideas at a faster rate. However, the spillovers are strong enough to guarantee a net positive effect of the international stock of knowledge on innovation.

The third reason to focus on the knowledge-generating sector is that in this sector international knowledge spillovers are likely to be the strongest and most pervasive. While the activity of production involves several country-specific factors, the activity of generating new ideas is largely cross-national. Scientists communicate intensely across countries, ideas are diffused promptly and technological innovations cross country borders. While we still allow for the existence of tacit (country-specific) knowledge, our specific interest is to identify the importance of international ideas in the development of new ideas. Existing studies on international diffusion of ideas based on patent citations (such as Jaffe et al., 1993; Branstetter, 2001; Peri 2005) have found that, while there is a large component of knowledge that remains localized in the country a significant portion diffuses internationally. Our study confirms that international knowledge is an important determinant of a country's innovation and even more so if the country is not a technological leader.

Finally, our paper is a step in a new, hardly explored, direction. Macroconomists have been all too fast in identifying technological progress with measured changes of total factor productivity. It is well known that this residual measure captures (together with technological progress) changes in efficiency in the use of factors, reallocation of factors across sectors, changes in (unmeasured) capacity utilization and so on. It is important to complement the TFP approach and consider 
seriously alternative measures of technological progress. Patented innovation is one of the most promising and measurable indices. Total factor productivity is an important construct, but economists should make an effort to understand the determinants of technological progress and measure directly its components.

The first part of our article explores the long run relationship between $R \& D$ resources and knowledge creation. We show that a panel of data for twenty-eight years and fifteen countries rejects the implication of strong scale effects of $R \& D$ while it does not reject weak scale effects implying a positive long run relationship between $R \& D$ resources and the stock of knowledge. We apply recent techniques of panel cointegration in order to test the long run relationship between $\mathrm{R} \& \mathrm{D}$ employment and the stock of national and international scientific/technological knowledge. Once we have identified this long run relation, we estimate the short run dynamics of the innovation process by means of an Error Correction Mechanism panel VAR (VECM). The impulse responses of this model allow us to evaluate the effect of an increase in $R \& D$ resources on knowledge created in the source country and any other country. By including a variable that captures the accessible international stock of knowledge we analyze the "external" impact of a country's R\&D on other countries' innovation both in the long and in the short run. In spite of the success of real business cycle theories, the short run behavior of innovation has been largely neglected by the dynamic empirical literature. Business cycle analysis has taken shocks to total factor productivity as exogenous and has analyzed their impact. Our paper, to the contrary, analyzes one important mechanism at the source of short-term fluctuations of productivity. In order to characterize correctly the short run behavior of a set of non-stationary variables, however, we need to account properly for their long run behavior. This is why we estimate an error correction mechanism that allows us to identify a response of $\mathrm{R} \& \mathrm{D}$ and innovation to shocks in the short and medium run, while accounting for long-run cointegration. This, to the best of our knowledge, has never been done in the literature ${ }^{2}$.

The rest of the paper is organized as follows. Section 2 presents a simple "idea-based" model of growth in which the idea-generating sector plays a key role. Within the context of these models we can test, using the dynamic properties of the knowledge generating sector, whether the data

\footnotetext{
${ }^{2}$ A partial and interesting exception is Shea (1999). Emphasizing the role of R\&D spending and patenting as sources of technological shocks, that article estimated the effects of those shocks on short run fluctuations for U.S. sectors. The study did not find a large effect of technological shocks on short run productivity fluctuations. However, the study did not apply the modern techniques for estimating cointegration and the Error Correction Mechanism panel VAR.
} 
support a model of endogenous or of semi-endogenous growth. We describe the idea-generating function and how we construct variables to measure $R \& D$ resources, new ideas, existing knowledge and their relationship. Section 3 describes the data for the panel of fifteen countries over the period 1973-1999. We show and test some of the basic time-series properties of the data before pursuing our estimation strategy. Section 4 studies the long run behavior of R\&D and innovation, testing the stationarity of knowledge growth rates and then estimating the panel cointegration between R\&D employment, domestic knowledge and international knowledge. Section 5 analyzes short run behavior using the VECM and shows some representative impulse response functions. Section 6 concludes the paper.

\section{Idea-Based growth Models and the R\&D sector}

\subsection{A Simple Framework}

The mechanism through which resources devoted to research and development (R\&D) are transformed into new knowledge is the centerpiece of several recent models of growth. These models, indeed, are referred to as "idea-based" models of growth ${ }^{3}$. More specifically, in these models the R\&D sector is the ultimate engine of economic growth. Both the first generation of "idea-based" models (such as Romer, 1990; Aghion and Howitt, 1992; Grossman and Helpman, 1991) and the second generation (Jones, 1995, Kortum 1997 and Segerstrom 1998) build on the analysis of the $\mathrm{R} \& \mathrm{D}$ sector to determine the long run behavior of productivity growth. For a given amount of resources allocated to $\mathrm{R} \& \mathrm{D}$, the parameters of the knowledge-producing function are the only ones responsible for the long run growth of knowledge which, in turn, determines productivity. In this sense the R\&D sector is crucial for long run growth. At the same time, the transitional fluctuations of the $\mathrm{R} \& \mathrm{D}$ sector together with those of the production sector (and of consumption-investment decisions) are responsible for transitional fluctuations of productivity due to the adjustments of the capital stock and knowledge stock (per worker) around their long run trajectories. Using a simple framework (similar to Jones, 2004) to illustrate this point let us consider an economy for which the production of output per worker, $y_{t}$, is given by:

\footnotetext{
${ }^{3}$ See Jones (2004) for a survey.
} 


$$
y_{t}=\left(B A_{t}^{\sigma}\right) k_{t}^{\alpha}
$$

where we assume a log-linear production function to simplify our discourse. $B A_{t}^{\sigma}$ is total factor productivity (TFP). It depends on a factor $B$ that captures efficiency in production and is mainly determined by institutions, geography and the legal structure of a country. These characteristics are slow to change so are assumed to be constant. TFP also depends (with an elasticity $\sigma>0$ ) on technological knowledge represented by the stock of total available scientific and technological ideas $A_{t}^{4} \cdot k_{t}$ is physical capital per worker and $\alpha<1$ is the elasticity of output with respect to physical capital, so that $k_{t}^{\alpha}$ satisfies the usual assumptions of decreasing marginal returns to capital and the Inada conditions. Taking derivatives of the logged variables with respect to time on both sides of equation (1) and denoting with $g_{x}$ the growth rate of variable $x$, we can write the growth rate of output per worker in period $t$ as:

$$
g_{y t}=\sigma g_{A t}+\alpha g_{k t}
$$

At any given time the growth rate of output per worker $\left(g_{y t}\right)$ is a linear combination of the growth rate of the stock of ideas $\left(g_{A t}\right)$ and capital per worker $\left(g_{k t}\right)$. In the long run, however, due to decreasing returns of physical capital, any growth model characterized by an aggregate production function as in (1) converges to a balanced growth path (BGP) in which $g_{y}^{*}=g_{k}^{*}$ (the stars denote BGP values $)^{5}$ The growth rate of output per worker in BGP is given by:

$$
g_{y}^{*}=\frac{\sigma}{1-\alpha} g_{A}^{*}
$$

On one hand, according to (2), the dynamics of knowledge growth, $g_{A t}$, affect the dynamics of income per capita as an important source of fluctuations and transitional dynamics. On the other hand, according to (3), the long run growth rate of ideas $\left(g_{A}^{*}\right)$, is the only determinant of long run GDP per capita growth for given parameters of the production function. The analysis of

\footnotetext{
${ }^{4}$ See Weil (2005), chapter 10, for a similar decomposition of total factor productivity.

${ }^{5}$ This result can easily be derived in a model with exogenous saving rate (as in Solow, 1956) or in a model with optimizing agents (as in Ramsey, 1928). See Barro and Sala i Martin (2004), Chapter 1 and 2, for details.
} 
the dynamics of $A_{t}$ in the short and long run is therefore an extremely informative and interesting empirical question for macroeconomists. Moreover, the distinction between models that deliver endogenous growth and models that deliver semi-endogenous growth depends exclusively on the dynamics of the idea-generating sector. We will return on this issue in section 2.4 below. From this point onwards we concentrate our attention on the knowledge-generating $(\mathrm{R} \& \mathrm{D})$ sector and its dynamics .

\subsection{The Knowledge-Generating (R\&D) Sector}

For its crucial role in determining the growth rate of productivity, the knowledge-generating sector is the focus of this paper. New ideas are produced by people working in R\&D who use their creativity and the existing stock of knowledge (made of non-obsolete ideas produced in the past). In the aggregate, the uncertainty in the rate of arrival of ideas can be reduced to a random noise so that new ideas, existing knowledge, and $R \& D$ resources can be represented as linked by a stable relationship (up to an error term) which can be viewed as a production function of new ideas. Omitting the error term (that we will re-introduce in the empirical section) the function can be expressed as:

$$
I_{i, t}=F\left(R \& D_{i, t}, A_{i, t}, A_{R O W i, t}\right)
$$

$I_{i, t}$ (for "Ideas") is the measure of new knowledge generated in country $i$ during year $t$. We assume that resources devoted to research during year $t$ affect the generation of ideas during that year $^{6} . R \& D_{i, t}$ is the employment in the private $\mathrm{R} \& \mathrm{D}$ sector for country $i$ during year $t . A_{i, t}$ is the stock of usable domestic knowledge measured as accumulated past ideas that were generated in country $i$ up to year $t-1$ and available at the beginning of year $t$. Similarly $A_{R O W i, t}$ is the stock of international knowledge measured as accumulated past ideas generated by countries in the rest of the world $(R O W)$ up to year $t-1$ and hence available at the beginning of year $t$. Existing ideas are a very important input in the creation of new ideas, this is why we include $A_{i, t}$ and $A_{R O W i, t}$ in the function $F$. The quantitative impact of existing knowledge on the generation of new ideas, however, can be positive, negative or zero due to the existence of two opposite effects.

\footnotetext{
${ }^{6}$ Early empirical studies, such as Hall et al. (1986) show the strong effect of R\&D on innovation within the same year. Past R\&D is captured, in this specification, by the accumulated stock of idea $A_{i, t}$ and $A_{R O W i, t}$.
} 
As illustrated by Caballero and Jaffe (1993) or Jones (2002), existing ideas widen the basis of knowledge usable to generate further innovation and may therefore have a positive impact on it (such effect has been named "standing on shoulders"). In particular, this effect could be so strong as to increase the rate of innovation as more knowledge becomes available. Alternatively, as ideas are discovered it may become harder to find new ones so that the effect of existing knowledge on innovation may be negative (this effect has been christened "fishing-out"). Our approach allows us to use the data to test whether the impact of existing knowledge on innovation is positive and large enough to generate accelerating innovation, positive but incompatible with accelerating innovation, or negative. Finally, in a world of closed economies with no exchange of knowledge across countries

only $A_{i, t}$ would be available to researchers of country $i$. In contrast, in a world of exchange of knowledge across countries, each country benefits from ideas discovered in the rest of the world. Several studies (Branstetter, 2001; Jaffe et al., 1993; Peri, 2005) show that the international diffusion of ideas is less than perfect and, in particular, less efficient than their diffusion within a country. For this reason we include knowledge created outside of a country as a separate input so that we are able to estimate the (external) impact of this factor on the generation of new ideas.

\subsection{Construction of Variables and Measurement Issues}

In the equations sketched above we have been rather vague in defining our variables. In particular we have not specified how to measure new knowledge $\left(I_{i, t}\right)$ and existing knowledge $\left(A_{i, t}\right)$ generated in country $i$ or the international stock of knowledge $A_{R O W i, t}$. In this section we describe in detail how to make equation (4) operational for the empirical analysis by constructing variables using the available data. Our main identifying assumption is that the number of new ideas produced in country $i$ during year $t, I_{i, t}$, is proportional to the number of inventions for which an international patent application is filed during year $t$ by an inventor residing in that country. Following an established tradition we utilize patent statistics to proxy the generation of innovative ideas. While not perfect, the correspondence between patents and new ideas has been extensively employed in economic analysis, and does seem reasonable both from a theoretical and an empirical point of view. According to the standards of patentability defined by the U.S. patent office, a patentable idea should be original, non-obvious and exploitable for economic profit. Moreover, many applied 
economists have drawn from the large pool of patent data, and used it to measure new ideas ${ }^{7}$. Similarly, theoretical economists (such as Romer, 1990 and Grossman and Helpman, 1991) have equated one idea to one patent in their models. In practice, however, there are two main sources of "noise" which prevent a perfect correspondence between patents and ideas. The first is that the propensity to patent a new idea may vary across countries. This is easily accounted for by introducing a country fixed effect. The second is that patents may have dissimilar "contents of ideas", with some patents containing many (or big) ideas and other relatively few (or less relevant) ideas $^{8}$. Since in our case, each unit of observation (country-year) includes the sum of a large number of patents, differences in the content of ideas for individual patents are likely to be averaged out. Moreover, we include a correction for the importance of a patent by weighting each of them by the number of citations received during the first 3 years. This correction, however, does not change much the results relative to the use of a simple patent count.

Our choices of selecting only international patents (filed in the U.S.) and of adopting the residence of the inventor as country of origin of the idea, have several advantages that make our dataset particularly appealing. First, by selecting patents taken in the United States we are likely to select only the most important (and potentially profitable) innovations originating from each country. As the U.S. is the most important world market any relevant innovation will be patented there. Only if an innovation is marginal or of very limited use will it not be worth the patenting cost in the U.S. Such choice, therefore, would tend to select "high-quality" ideas, which should be the most important for their effects on productivity. These ideas are also the ones that are most likely to benefit from international diffusion of knowledge. Second, the U.S. patent data allow us to locate the residence of the inventor and use it as the idea's country of origin. Aggregate statistics from the world industrial property office (WIPO) identify only the location of the headquarters of the applying company. The literature agrees that the first is a better way of identifying where the idea was developed as the location of the headquarters of a company is often different from that where R\&D was performed ${ }^{9}$. Third, the NBER patents and citations data report the citations between patents and allows us to construct a measure of the importance of a patent (based on the received citations) that in turn can be used to weight each of them in a more accurate measure of

\footnotetext{
${ }^{7}$ See Griliches (1990) for a survey.

${ }^{8}$ See, for instance, Jaffe and Trajtenberg (2002), Chapter 2.

${ }^{9}$ See Jaffe et al.(1992) and Jaffe and Trajtenberg (2002) for an accurate discussions of this issue.
} 
innovation.

We can summarize the relationship between patents and ideas, allowing for country-specific propensity to patent, as: $P a t_{i, t}=\varkappa_{i} I_{i t}$ where $P a t_{i, t}$ is the number of patent applications filed with the US patent office by inventors living in country $i$ during year $t$ and $\varkappa_{i}$ is the country-specific propensity to patent. The choice of the application year to capture the generation of an idea is appropriate because the process of obtaining a patent is slow. While an application is filed very early after the discovery took place, the patent may be granted several years later (see Jaffe and Trajtenberg, 2002, Chapter 13).

In order to study the relationship defined by (4) we assume that the mapping $F(., .,$.$) can be$ approximated by a log-linear function as follows:

$$
\ln \left(P a t_{i, t}\right)=\ln \left(\varkappa_{i}\right)+\lambda \ln \left(R \& D_{i, t}\right)+\phi \ln \left(A_{i, t}\right)+\xi \ln \left(A_{R O W i, t}\right)
$$

Equation (5) states that the (log) number of patent applications originating in country $i$ during year $t$ is a function of a country fixed effect $\left(\ln \left(\varkappa_{i}\right)\right)$, the $(\log )$ level of $R \& D$ (personnel employed in $\mathrm{R} \& \mathrm{D}$ in full time equivalents) of country $i$ during year $t\left(R \& D_{i, t}\right)$, the stock of knowledge generated in country $i\left(A_{i, t}\right)$, as well as in the rest of the world $\left(A_{R O W i, t}\right)$ and available at the beginning of year $t^{10}$. The coefficient $\lambda$ captures the impact of $\mathrm{R} \& \mathrm{D}$ resources on patenting, while $\phi$ and $\xi$ capture, respectively, the effects of domestically-generated and internationally-generated knowledge on patenting. The stock variable $A_{i, t}$ captures the accumulated, non-obsolete knowledge originating from country $i$. We assume that the stock of knowledge is continually increased by the addition of new ideas and, at the same time, it is continually decreased by a constant depreciation (obsolescence) rate $\delta$ that captures the fact that new ideas may displace (or improve on) old ideas $^{11}$. Therefore, using the correspondence between patents and ideas and omitting the country fixed factors (that could be factored out and bundled with the country fixed effects $\varkappa_{i}$ ) the variable

\footnotetext{
${ }^{10}$ To understand how patents (measured as a flow) are produced using R\&D (also a flow of resources) and knowledge (measured as a stock), it is useful to think of a standard aggregate production function. GDP at the aggregate level (measured as a yearly flow) is produced using labor inputs (a flow of worked hours) and Capital stock. Knowledge plays the role of a stock variable in (5) and we would like to measure its services but we can only measure its total amount.

${ }^{11}$ We choose a depreciation rate to be within the range estimated using data on patent-citations (Caballero and Jaffe, 1992) and close to what is chosen as depreciation for the R\&D stock (Keller, 2002 ). Such rate is set to $\delta=0.1$. We conduct robustness checks for the case of $\delta=0.15$, and $\delta=0.08$ and we do not find any significant variation in the results.
} 
$A_{i, t}$ is defined by the following recursive formula:

$$
A_{i, t+1}=P a t_{i, t}+(1-\delta) A_{i, t}
$$

Assuming that the accumulation of knowledge in the past has been compatible with a balanced growth path, we construct the initial value $A_{i t_{0}}$, (following the perpetual inventory method ${ }^{12}$ ) as:

$$
A_{i t_{0}}=\sum_{t=0}^{\infty}=\frac{P_{a t_{i t_{0}}}}{\left(1+\overline{g_{i}}\right)^{t+1}}(1-\delta)^{t}=\frac{\text { Pat }_{i, t_{0}}}{\left(\overline{g_{i}}+\delta\right)}
$$

where $\overline{g_{i}}$, is the growth rate of patenting in country $i$ in the five years between $t_{0}$ and $t_{0}+5$, and $\delta$ is equal to 0.1 . The value obtained from (7) is, at best, a rough estimate of the initial stock of knowledge in country $i$. However, we use $t_{0}=1963$ as the first year in which patent data are available while we begin our analysis of cross-country innovation in 1973. This allows us to reduce the effect of any mistake due to an imprecise estimate of the initial stock of knowledge. The impact of $A_{i, 1963}$ on $A_{i, 1973}$ is, in fact, diluted by the accumulation over ten years and is rather small. Most of the existing literature on knowledge spillovers (Coe and Helpman, 1995; Funk, 2000) used the stock of accumulated past $R \& D$, rather than of patents, to measure the international stock of knowledge. There are several reasons, however, to prefer the choice of accumulated patents in our context. First, R\&D resources (such as scientists and labs) are excludable while the ideas generated with them (patents) are not. The external effect on innovation comes from knowledge generated abroad (rather than directly from R\&D) and accumulated patents measure it more accurately. Second, as data on patents are available beginning in 1963 , but data on R\&D only since 1973, using the perpetual inventory method and equation (7) to initialize the stock would imply higher imprecision when using accumulated $\mathrm{R} \& \mathrm{D}$ rather than accumulated patents. Third, $\mathrm{R} \& \mathrm{D}$ resources take some time (one year according to specification 5), to become available as domestic and international knowledge so that only $A_{i, t+1}$ and $A_{R O W i, t+1}$ contain ideas generated using $R \& D_{i, t}$. The timing of $\mathrm{R} \& \mathrm{D}$, therefore, may be leading (one or more periods) its impact on innovation in a foreign country. Constructing the lagged stock of knowledge would imply that we lose further initial observations for each country. Ultimately, however, as R\&D in a country is the most important determinant of patenting, the two measures (stock of R\&D and of stock of patents)

\footnotetext{
${ }^{12}$ See Young (1995), footnote 16 pp. 652.
} 
are highly correlated in the long run. Studies limited to the long run analysis (such as Coe and Helpman, 1995; Funk, 2000) could use either measure to obtain similar results (see section 4). The reasons to prefer the stock of patents are more relevant in the short run analysis which is a specific contribution of this paper.

We construct $A_{R O W i, t}$ as the simple sum of the stock of ideas generated in countries other than $i$ by year $t-1$, and available at the beginning of year $t$. Namely, $A_{R O W i, t}=\sum_{j \neq i} A_{j, t}$. The choice of a simple sum is driven by three considerations. First, Keller (1998) showed that an unweighted sum of external R\&D works just as well as a trade-weighted sum when measuring the external effect of research. Second, Edmond (2001) has shown that the specification with unweighted sum is more robust to different specifications and estimation methods than the weighted one. Finally Peri (2005) finds that international flows of ideas are much less localized than trade flows and most of the attrition takes place within a country. Ideas that flow beyond the country border (internationally) are likely to diffuse very broadly. Weighting the contribution of foreign ideas by trade shares would, therefore, incorrectly reduce their impact so that it is better to take simply their unweighted sum.

\subsection{Long run Implications of Strong and Weak Scale Effects}

We divide both sides of equation (6) by $A_{i, t}$ and take natural logs. Substituting for Pat $t_{i, t}$ its expression from (5), and for $A_{R O W i, t}$ its definition given above, we obtain the following relation, which is the basis of our long run econometric analysis:

$$
\ln \left(g_{A i, t}+\delta\right)-\ln \left(\varkappa_{i}\right)=\lambda \ln \left(R \& D_{i, t}\right)+(\phi-1) \ln \left(A_{i, t}\right)+\xi \ln \left(\sum_{j \neq i} A_{j, t}\right)
$$

where $g_{A i, t}=\left(A_{i, t+1}-A_{i, t}\right) / A_{i, t}$ is the growth rate of the stock of ideas generated in country $i$ in year $t$. This equation holds in each period and can be used to study the dynamics of the knowledge stock which, according to (2) and (3), has direct bearings on the dynamics of output per worker. If the stock of ideas converges to a (stochastic) balanced growth path then the term $\ln \left(g_{A i, t}+\delta\right)-\ln \left(\varkappa_{i}\right)$ on the left hand side of (8) converges to a country-specific stationary stochastic process. In this case equation (8) implies a stable (stationary) long run relation between the variables $\ln \left(R \& D_{i, t}\right)$, $\ln \left(A_{i, t}\right)$ and $\ln \left(A_{R O W i, t}\right)$ on the right hand side. In particular, if each of the three variables is 
non-stationary (as is the case), convergence to a stochastic balanced growth path implies that there must be a cointegration relation among them, (i.e. a linear combination that is stationary). The cointegration vector, standardizing by the coefficient of $\ln \left(A_{i, t}\right)$, would be $(-1, \mu, \gamma)$ where $\mu=\lambda /(1-\phi)$ and $\gamma=\xi /(1-\phi)$. It can be estimated using the following regression

$$
\ln \left(A_{i, t}\right)=\mu \ln \left(R \& D_{i, t}\right)+\gamma \ln \left(\sum_{j \neq i} A_{j, t}\right)+s_{i, t}
$$

where we have collected all the stationary variables (deterministic and stochastic) in the term $s_{i, t}$. From the estimates of this cointegration vector we are also able to establish whether $\xi$ is larger, smaller, or equal to 0 (as its sign will be the same as the sign of $\gamma$ ). Alternatively, if the stock of ideas does not converge to a balanced growth path so that $g_{A i, t}$ is not stationary in the long run but increases with the levels of $\ln \left(R \& D_{i, t}\right), \ln \left(A_{i, t}\right)$ and $\ln \left(A_{R O W i, t}\right)$ then no cointegration exists between those variables and the system would experience stocks of ideas diverging across countries and experiencing explosive growth over time.

The tests of stationarity of $g_{A i, t}$ and of cointegration between the variables $\ln \left(R \& D_{i, t}\right), \ln \left(A_{i, t}\right)$ and $\ln \left(A_{R O W i, t}\right)$ allow us to discriminate between the two alternative idea-based models of growth (endogenous vs. semi-endogenous). If $g_{A i, t}$ is stationary then, in the long run, the levels of R\&D resources and world knowledge determine (are cointegrated with) the level of knowledge of a country (and therefore the level of its productivity). This is a typical property of the semi-endogenous models of growth such as Jones (1995) and Segerstrom (1998) in which the size of the R\&D sector affects the level of domestic knowledge through a weak scale effect. Moreover, within this case a positive sign of the coefficient $\gamma$, would be evidence of a net "standing on shoulders" effect, while a negative sign of $\gamma$ would imply that the "fishing-out" effect prevails. Alternatively, if $g_{A i, t}$ is non-stationary then levels of R\&D resources and stocks of knowledge (on the right hand side of 8) determine the growth rate of knowledge of a country $\left(g_{A i, t}\right)$ and, as a consequence, the growth rate of its total factor productivity. In turn, this is a typical property of the endogenous models of growth such as Romer (1990), Aghion and Howitt (1992) and Grossman and Helpman (1991). In this case R\&D would have a strong scale effect, implying that its level affects the growth rate of the stock of ideas. The novelty of our approach, relative to a previous test performed by Jones (1995), is our cross-country specification and our direct measure of scientific/technological knowledge, based on 
patents, rather than its indirect measure, based on total factor productivity. Testing the scale effect of $\mathrm{R} \& \mathrm{D}$ on knowledge generation (rather than on TFP) gives endogenous growth models the best chance at succeeding over semi-endogenous models. In fact the non-rival nature of knowledge should be strongest when it is used by international researchers to generate new knowledge (rather than goods). The rejection of endogenous growth models in favor of semi-endogenous ones, even using this empirical setting, is very strong evidence for preferring the second type of models as empirical tools. At the same time we find strong evidence of a net "standing on shoulders" effect $(\gamma>0)$, i.e. that existing international knowledge increases the innovation of countries. We then use equation (5) in order to identify and estimate the effect of R\&D and innovation shocks on creation of ideas

in the short run. Equation (5) implies that patent applications in period $t\left(P_{a t, t}\right)$ are affected by R\&D resources employed in the same year, and by knowledge generated within the country, $A_{i, t}$, or outside of it, $A_{R O W i, t}$, up to the beginning of the year. In turn, innovation generated during year $t\left(P_{i, t}\right)$ only becomes available as national and international knowledge beginning with the following year $\left(A_{i, t+1}, A_{R O W i, t+1}\right)$. These assumptions on the timing of innovation relative to R\&D provide the identifying restrictions needed to order equations and to estimate our Error Correction Mechanism (see section 5.2).

\section{Data: Description and Time-Series Properties}

\subsection{Data Description}

Our empirical analysis is performed on data from fifteen OECD Countries during the period 19731999. These fifteen countries, taken together, account for about $90 \%$ of the world $R \& D$ and for 97-98\% of the total U.S. granted patents. R\&D resources are measured by personnel working in the R\&D sector in full-time equivalents. The data on R\&D are from the ANBERD, OECD-STAN data set. The patent data, grouped by country of residence of the first inventor and by year of application are obtained by aggregating individual patents from the NBER Patent and Citations Data set described in detail in the book by Jaffe and Trajtenberg (2002) and publicly available at http://www.nber.org/patents/. The dataset includes over 3 million patents granted by the United States patent office between the years 1963 and 1999. We measure of Pat $t_{i, t}$ by the total number of patent applications by residents of country $i$ during year $t$, and we weight each patent by the 
factor $\left(1+\mu_{3}\right)$ where $\mu_{3}$ is the average number of yearly citations received by the patent during the first three years after it has been granted. This accounts for the importance of the innovation embedded in the patent. As argued in several articles ${ }^{13}$ citations are, on average, an indicator of the importance of a patent and of its market value. For robustness we also conduct our analysis using simple patent counts and the results are very similar.

Table 1 shows the average values of the variables of interest, by country, for the whole period 1973-1999. The first column shows the average full-time equivalent units of personnel in R\&D, the second shows the average number of patent applications per year, the third and fourth report the average values of the constructed stocks of knowledge $\ln \left(A_{i, t}\right)$ and $\ln \left(A_{R O W i, t}\right)$. Large variations in total R\&D resources and total patenting exist across these countries. The US is the technological leader by a large margin employing and average of almost 1.7 million full-time equivalent persons in its R\&D sector and filing more than 70,000 patent applications every year. Japan, Germany and the United Kingdom are distant second, third and fourth in terms of R\&D and patents. Ireland is the smallest innovator in our sample, filing an average of merely 57 patent applications each year. The averages over the whole time-period mask the interesting time-evolution of the variables in each country. Before performing formal tests on the time-series properties of these variables, we illustrate their behavior for a subset of G7 countries in Figure 1 to 3. Figure 1 shows the behavior of the variable $\ln \left(R \& D_{i, t}\right)$ for the seven largest economies over the 1973-1999 period. In spite of different average growth rates (from $0 \%$ of the UK to a positive $6 \%$ per year for Canada) the picture confirms a common upward trend (except for the UK) as well as high persistence of year to year movements. Also, some countries exhibit detectable differences over different periods. Japan, for instance, increased its R\&D employment largely up to year 1990, and later experienced very slow growth or possible stagnation. Similarly, Italy experienced growth in R\&D resources only up to the early nineties. The countries with fastest growing R\&D employment for our sample were Spain and Finland (not among the G7) with annual growth of 10 and $11 \%$ respectively. Figure 2 illustrates the time behavior of (log) patent applications per year for the G7 countries in the 1993-1999 period. This variable, which measures new knowledge generated in the seven countries, also shows a general upward trend. Some fluctuations especially during the 1990's are also visible. When we consider the whole sample, the country that experienced the fastest growth in patent application was Ireland

\footnotetext{
${ }^{13}$ See for instance Jaffe and Trajtenberg (2002), Chapter 2 and Hall et al. (2005).
} 
with $12 \%$ annual increase, while Great Britain was the one with slowest growth (annual $0.1 \%$ ). Finally, Figure 3 shows the behavior of the constructed variable $\ln \left(A_{i, t}\right)$ for each one of the G7 countries during the usual period. The variables are trending up and Japan exhibits a particularly fast-growing stock of knowledge. The persistent upward movements in the variables $\ln \left(R \& D_{i, t}\right)$ and $\ln \left(A_{i, t}\right)$ suggest that they could be non-stationary and have a stable relationship (cointegration) over time. We move, therefore, to perform formal tests of non-stationarity and cointegration of the variables of interest.

\subsection{Test of Unit Root of R\&D and Stocks of Knowledge}

The process of knowledge accumulation, captured by the increase over time of the variable $\ln \left(A_{i, t}\right)$, suggests the variable is non-stationary. Previous studies (e.g. Jones 1995) found that employment in $R \& D$ was steadily and persistently growing in technologically leading countries during the last decades. Therefore, we have reasons to believe that the variable $\ln \left(R \& D_{i, t}\right)$ is non-stationary as well. In a short time series of yearly data (26 observations), it is particularly hard to discern nonstationarity. To formally test this property we rely on panel unit roots tests that exploit both the cross section and the time series dimension of the data.

There are several statistics that can be used to test for a unit root in panel data. Specifically, we want to test for non stationarity against the alternative of trend stationarity, allowing for a different intercept for each country. We employ the test proposed by Im et al. (2003) as it allows each panel member to have different autoregressive parameters and short time dynamics under the alternative hypothesis of trend stationarity. As the test procedure requires that the observations are not correlated across countries in each period, we first remove a time specific common effect by differencing out the common period average. We then perform a test based on the average of the adjusted Dickey-Fuller (ADF) test statistics calculated independently for each member of the panel, with one lag to adjust for auto-correlation. The test statistics, (adjusted using the tables in $\mathrm{Im}$ et al.,2003) are distributed as $\mathrm{N}(0,1)$ under the null of a unit root. Large negative values lead to rejection of a unit root in favor of stationarity. We do not require all the series for all countries to be non-stationary since the value of the test is the average of the ADF for individual countries. Table 2, Columns one to three, report the $\operatorname{Im}$ et al. (2003) test statistics for the variables $\ln \left(A_{i, t}\right), \ln \left(A_{R O W i, t}\right)$ and $\ln \left(R \& D_{i, t}\right)$. In no case can we reject the null of non-stationarity 
at standard levels of significance. Furthermore, no country exhibits ADF statistics relative to $\ln \left(R \& D_{i, t}\right), \ln \left(A_{i, t}\right)$ and $\ln \left(A_{R O W i, t}\right)$ that are larger (in absolute value) than the threshold for rejecting the unit-root hypothesis.

The test proposed by Im et al. (2003), however, is not robust to mispecification of time trends or short run dynamics if the effect of the common component varies across countries. Therefore we also perform a panel unit-root test which is robust to the presence of cross-sectional dependence. This test follows Pesaran (2003) and is reported, for each variable and country, in the fourth through sixth column of Table 2. Instead of basing the unit root tests on deviations from the estimated factors, we augment the standard DF (or ADF) regressions with the cross section averages of lagged levels. Standard panel unit root tests can now be based on the simple averages of the individual cross sectionally augmented ADF statistics (denoted by CADF in Table 2). The individual CADF statistics facilitate a modified version of the t-bar test proposed by Im et al. (2003). Even in this case the test never rejects the null of non-stationarity for any of the three variables. Overall, the formal tests do not reject our priors, which were also supported by the direct visual inspection of the data: shocks to R\&D and to the domestic or international stock of knowledge are very persistent and these variables can be represented by non-stationary processes.

\subsection{Stationarity of Growth Rates: Test of Strong Scale Effects}

Next, we test for a unit root in the first time-differences of the variable $\ln \left(A_{i, t}\right), g_{A i, t}$, the growth rate of locally generated knowledge. In this case the alternative hypothesis is stationarity without a trend, since any time trend in levels is removed by differencing. We use the same tests that we used in section 3.2 above. A rejection of the null of non-stationarity would be evidence in favor of convergence of the stock of knowledge to a balance growth path. Table 3 reports the unit-root tests (Im et al., 2003; and Pesaran, 2003) applied to the variables $g_{A i, t}$ as well as to the growth rates of $R \& D_{i, t}\left(\Delta \ln \left(R \& D_{i, t}\right)\right)$ and of the international stock of knowledge $A_{R O W i, t}\left(\Delta \ln \left(A_{R O W i, t}\right)\right)$. The test statistic is negative and large in each case. For every one of these growth rates we are able to reject the null hypothesis of non-stationarity at the $1 \%$ significance level. Hence, this test provides a clear rejection of the existence of a strong scale effect in the production of knowledge. As $g_{A i, t}$ is stationary, the variable $\ln \left(A_{i, t}\right)$ converges to a stochastic balanced growth path. This implies that there is a long run relationship between the variables $\ln \left(A_{i, t}\right), \ln \left(A_{R O W i, t}\right)$ and $\ln \left(R \& D_{i, t}\right)$, (which 
are all integrated processes of order one, $I(1))$ so that their linear combination expressed by $(8)$ is stationary. In the long run the three variables move together so that the level of $R \& D_{i, t}$ of a country and the international stock of knowledge $A_{R O W i, t}$ determine the stock of knowledge created in country $i, \ln \left(A_{i, t}\right)$. The remainder of our analysis proceeds on the assumption, supported by the tests performed above, that all log level variables follow non-stationary, $I(1)$, processes while all $\log$ differenced variables follow stationary, $I(0)$, processes.

\section{The long run Dynamics: Estimating the Cointegration Relation}

Thus far the results point to the possible existence of a cointegration relation between the variables $\ln \left(A_{i, t}\right), \ln \left(A_{R O W i, t}\right)$ and $\ln \left(R \& D_{i, t}\right)$.We estimate this relationship by dynamic ordinary least squares (DOLS) using the whole panel of 15 countries and 26 years. The environment that we study imposes homogeneity on the cointegration vector across countries but allows for country-specific effects and time trends as well as a common time effect. As in Phillips and Moon (1999), Kao (1999) and Pedroni (1999), the errors are assumed to be independent across countries. Therefore, as in the single-equation environment, this estimator sacrifices asymptotic efficiency because it does not take into account the cross-equation dependence in the equilibrium errors ${ }^{14}$.

This method of exploiting the cross-sectional dimension of the data while respecting the time series properties, without aggregating or pooling, allows us to address the problem of inconsistent estimates in dynamic heterogeneous panels identified by Pesaran et al. (1999). Finally, the use of DOLS as opposed to other cointegration estimators is justified by recent work by Kao et al. (1999), which shows that it performs better than other single-equation cointegration estimators in panels of up to size $\mathrm{N}=20$. In practical terms, the estimation of the equation by DOLS involves adding leads and lags of the first differences of the $I(1)$ regressors in equation (9). Thus, all nuisance parameters, which represent short run dynamics, are $I(0)$ and uncorrelated with the error term (by construction). This procedure corrects for the possible endogeneity of the non-stationary regressors and gives estimates of the cointegration vector which are asymptotically efficient when the error

\footnotetext{
${ }^{14}$ In contrast to previous analyses of panel cointegration vector estimators, the asymptotic distribution of panel DOLS under cross-sectional dependence is easy to obtain. Mark et al. (2003) and Kao et al. (1999) studied the properties of panel dynamic OLS under the assumption of independence across cross-sectional units. Pedroni (1999) and Phillips and Moon (1999) study a panel fully modified OLS estimator also under cross-sectional independence. Moreover, the asymptotic theory employed in these papers allows both $T$ and $N$ to go to infinity.
} 
terms are independent across countries. All variables and nuisance parameters corresponding to the dynamic terms are allowed to vary across countries.

In order to estimate the cointegration relation between $R \& D$ and stock of ideas we re-write expression (9) adding two lags of the differenced variables as follows ${ }^{15}$ :

$$
\begin{aligned}
\ln \left(A_{i t}\right)= & c_{i}+\lambda_{i} t+\mu \log \left(R \& D_{i, t}\right)+\sum_{j=1}^{2} \mu_{i} \Delta \ln \left(R \& D_{i, t-j}\right)+ \\
& +\gamma \log \left(A_{R O W i, t}\right)+\sum_{j=1}^{2} \gamma_{i} \Delta \ln \left(A_{R O W i, t-j}\right)+\epsilon_{i, t}
\end{aligned}
$$

The first two rows of Table 4 report the estimates of $\mu$ and $\gamma$ which capture the long run elasticity of knowledge generated in a country to R\&D employment and to knowledge created in the rest of the world. The variance-covariance matrix of the coefficients is consistently estimated by applying the dynamic panel variance estimator proposed by Mark et al. (2003) ${ }^{16}$. As different countries may exhibit permanent differences in their innovation generating (or patenting) process we allow for country-specific fixed effects, $c_{i}$, in each specification. We include a country specific time-trend in most of the specifications (Specification II, III, V and VI) to control for time-effects. Finally specification IV includes a common time fixed effect as a way of capturing common movements over time.

The regression identifies the long run relationship between the variables in a way that is robust to the presence of short run dynamics. Transitional dynamics have a second order effect on the estimated long run relationship and they can be treated as a nuisance parameter in the estimation and testing procedure. We can relax the exogeneity assumptions that have been required in earlier approaches without the need for external instruments due to the superconsistency properties of the panel cointegration regression, which identifies the long run relationship even in the presence of endogeneity.

Column I of Table 4 reports the estimates when we only control for country fixed effects.

\footnotetext{
${ }^{15}$ The lag length can be determined by Campbell and Perron (1991) top-down t-test approach.

${ }^{16}$ To control for potential serial correlation in $\epsilon_{i, t}$ we have computed the Newey-West estimates of the long run variance.
} 
Both coefficients are estimated very precisely. A $1 \%$ increase of a country's R\&D employment is associated with a $0.79 \%$ increase in the domestically generated stock of scientific and technological knowledge (the standard error is $0.06 \%$ ). At the same time a $1 \%$ increase of the international stock of knowledge is associated, in the long run, with a $0.56 \%$ increase in domestically generated knowledge (with a standard error of $0.06 \%$ ). These point estimates are very reasonable. First, micro studies of the effect of R\&D on innovation find similar elasticities. For instance Branstetter (2001) uses firm-level data and finds an elasticity of 0.72. Pakes and Griliches (1980) found a value of 0.61. Peri (2005), using data on sub-national regions, found values between 0.6 and 0.8 . At the same time, the existing estimates of the elasticity of domestic innovation to international accessible knowledge are between $50 \%$ and $80 \%$ of the elasticities to own R\&D (see Griliches, 1992). Moreover these estimates are qualitatively consistent with the macroeconomic finding of a positive long run relation between R\&D and Total Factor Productivity (e.g. Coe and Helpman, 1995; Kao et al., $1999)^{17}$.

Introducing a country-specific time trend (Specification II, III and V) cuts the point-estimates of the two elasticities in half. However, both coefficients remain positive and very significant. The elasticity of R\&D employment is close to 0.30 in specification II, and the effect of international knowledge reduces to 0.168 . Specification III shows that using the simple count of patents (rather than their count weighted by average number of citations within 3 years) as measure of innovation does not entail any major change in results. The impact of international knowledge on domestic knowledge increases somewhat (to 0.385 ), while the impact of $\mathrm{R} \& \mathrm{D}$ on domestic knowledge is unchanged. Specification IV introduces year fixed effects in place of (country specific) trends. As much of the variation of the international stock of knowledge is from year to year we are worried that common fluctuations may be mistaken for the effect of international knowledge. The most demanding specification (IV) of Table 4 requires that the effects of international knowledge on domestic knowledge be identified only by variations specific to each country over time. The estimates reveal that the effect of international knowledge remains very strong and significantly positive at 0.276 . The effect of $\mathrm{R} \& \mathrm{D}$ is 0.74 , close to the estimate in the basic specification. The estimate of the series of time effects $t$ in specification IV (not reported) reveals the common cyclical

\footnotetext{
${ }^{17}$ If we use the sum of the contemporaneous flow of $R \& D$ resources in the rest of the world as measure of international knowledge the coefficient on this variable equals 0.76 (s.e. 0.077 ). However, the coefficient on own $R \& D$ spending would be estimated more imprecisely due to strong collinearity.
} 
behavior of knowledge variables in the panel. However that series also demonstrate stationary behavior ${ }^{18}$. Altogether, the consistently positive and significant estimates of the coefficient $\gamma$ reported in Table 4 contribute strong evidence in favor of the existence of a "standing on shoulders" effect that implies a positive effect of knowledge on innovation. However, they also prove decreasing returns to innovation as there is no evidence of a strong scale effect in the R\&D sector.

Finally, specifications V and VI inquire into the relative impact of international knowledge on innovation in countries at the technological frontier vis-a-vis other countries. Due to concentration of $R \& D$ activity, the United States, which is the largest innovator, generates more than half of the world innovation. The seven largest economies combined (G7 countries) perform the large part of R\&D and produce the vast majority of innovation in the OECD group. Moreover, we can think that the ideas generated in countries at the technological frontier have higher quality and more visibility than those generated in other countries. This would imply that the impact of international knowledge on innovation of a country will be asymmetric. While the technological leaders benefit mostly from their own R\&D the technological followers heavily depend on the international flow of knowledge to "feed" their innovative activity. Coe and Helpman (1995) and Peri (2005) show that the stock of knowledge generated among the technological leaders has a particularly strong effect on productivity growth and innovation of the followers, but not vice-versa. In specification $\mathrm{V}$ we simply consider the U.S. as the world technological leader and omit it from the sample. An early paper by Eaton and Kortum (1996) estimated that the U.S. is the only country in the world in which more than half of the technological progress stems from domestically generated ideas (rather then from international knowledge). By estimating the cointegration relation among technological followers (non-US) we expect to find that the relevance of international knowledge for innovation is larger than for the whole sample (including the U.S.). The estimates confirm that this is true. The effect of international knowledge in specification $\mathrm{V}$ is almost twice as large as the estimate in the corresponding specification II (that includes the US). Similarly, specification VI splits the sample between G7 countries and the rest and estimates the cointegration relation separately for each sample. We construct the stock of international knowledge for each country (within or outside the G7) adding knowledge generated in the "complementary" country group only. That is, in specification $\mathrm{VI}(\mathrm{a})$ the coefficient on the variable $\ln \left(A_{R O W i, t}\right)$ estimates the importance of ideas generated in

\footnotetext{
${ }^{18}$ The series of estimated $\theta_{t}$ is available from the authors upon request.
} 
the G7 on knowledge created in non-G7 countries, while the coefficient on the same variable in specification VI(b) represents the importance of knowledge generated outside the G7 on knowledge created in G7 countries. Consistently with previous findings the stock of international knowledge is extremely relevant in affecting domestic creation of knowledge for technological followers, with an elasticity close to 0.75 (recall that the average elasticity of innovation to international knowledge was 0.168 , while for non-US was 0.366 ). We also find that for non-G7 countries the effect of own R\&D does not seem particularly significant. In contrast, G7 countries rely mostly upon their own $\mathrm{R} \& \mathrm{D}$ to generate knowledge while international knowledge has no positive impact (in fact we estimate a somewhat puzzling negative effect). The existence of international knowledge flows seem, therefore, more relevant for the innovative activity of countries behind the technological frontier.

\subsection{Panel Cointegration Test}

Under the assumption of cointegration between $\ln \left(A_{i, t}\right), \ln \left(A_{R O W i, t}\right)$ and $\ln \left(R \& D_{i, t}\right)$, the estimated residual from regression (10), should be stationary. As a final test of the hypothesis of weak scale effects (against strong scale effects), we employ an Augmented Dickey Fuller panel cointegration test. This test is analogous to the Im et al. (2003) ADF test that we used in Section 3. These panel cointegration tests are essentially univariate extensions of the original panel unit root tests based on the residuals from a first-step cointegration regression in the spirit of the two-step cointegration test approach by Engle and Granger $(1987)^{19}$.

Table 5 reports several tests of cointegration based on different statistics ${ }^{20}$. The first two test statistics, PC1 and PC2, apply to the case in which the cointegration vector is assumed to be the same across all countries (Pedroni,1995). The other seven tests are developed in Pedroni (1999) and do not impose this homogeneity restriction. Using the cross-section dimension of the data set while respecting the time series properties of the data (without aggregating or pooling) addresses the problem of inconsistent estimates in dynamic heterogeneous panels identified by Pesaran et al. (1999). Pedroni (1999) derives seven different statistics for testing the null of no cointegration; four are based on pooling along the within-dimension and the remaining three are obtained by pooling along the between-dimension. The null hypothesis is that the first autoregressive coefficient of the

\footnotetext{
${ }^{19}$ For an overview and further references to recent literature on the subject, see Banerjee (1999).

${ }^{20}$ The lag lengths for the ADF tests are chosen to ensure that the error terms are white noise.
} 
residual series is equal to unity (i.e. no cointegration between variables). Under the alternative hypothesis, in the case of the within-dimension tests the same coefficient is strictly less than one and equal for all members of the panel. In the case of the between dimension test, the autoregressive coefficient is less than unity but may differ across countries. The within-dimension based statistics is referred to as panel cointegration tests, while the between-dimension one as group mean panel statistics. All tests, after an appropriate standardization, follow a normal distribution. In particular, Pedroni (1999) shows that under the alternative hypothesis (cointegration) the panel variance statistics diverge to positive infinity and the right tail of the normal distribution is used to reject the null hypothesis (no cointegration). For the other six test statistics, which diverge to negative infinity under the alternative hypothesis (of cointegration), large negative values reject the null of no cointegration ${ }^{21}$. Seven of the nine tests presented in Table 5 reject the null hypothesis of no cointegration at the $1 \%$ significance level. The two statistics that fail to reject the no cointegration hypothesis are the group-rho statistic and the variance test statistic. As shown in Pedroni (2004), the group-rho statistic is undersized in small panel and it is the most conservative test. The panel-v statistics tend to have the best power relative to the other statistics when the panel is fairly large, which is not our case.

Table 6 presents an alternative approach to testing for cointegration and the number of cointegration relations in heterogeneous panel data based on the likelihood ratio inference for vector autoregressive models developed in Johansen $(1988,1991,1995)$. The LR-bar test statistics proposed by Larsson et al. (2001) is given by the average of the individual likelihood ratio cointegration rank trace test statistics over the panel individuals. As for the individual likelihood-ratio rank test, used to determine the number of cointegration relations " $r$ ", we can proceed sequentially from $r=0$ to $r=3$ until we fail to reject the null hypothesis. The trace statistic tests the null hypothesis of $r$ cointegration relations against the alternative of $j$ cointegration relations, where $j$ is the number of endogenous variables $(j=3$ in our case), for $r=0,1,2$. The alternative of $j$ cointegration relations corresponds to the case where none of the series has a unit root and a stationary VAR may be specified in terms of the levels of all of the series. Table 6 presents the individual countryby-country and panel test results. Due to the short time dimension of our panel only one lag $(k=1)$ is considered. The results show that the most commonly selected rank is one. The panel

\footnotetext{
${ }^{21}$ For a more technical and detailed description of how to construct the tests we refer to Pedroni (1999)
} 
test results, presented at the bottom of Table 6 , suggest that $r=1$ is the largest order. Hence this test supports the assumption that there is one cointegration relation in the panel.

\section{The short run Impulse Response Function}

\subsection{The Error Correction Mechanism Panel VAR}

While departures from the cointegration relation between $R \& D$ resources and stock of knowledge cannot last in the long run, the innovation process is subject to shocks in the short run. There could be shocks to the amount of resources allocated to research or to the productivity of researchers in generating new ideas. In order to analyze the propagation and impulse response to such shocks in the short run, we adopt an error correction representation of our dynamic relationship between $\ln \left(R \& D_{i, t}\right)$ and $\ln \left(A_{i, t}\right)$. In particular, we consider the change of each variable as depending on the past changes of the other variables (a VAR in differences) but we include a term that captures the deviation from the estimated long run relationship. This disequilibrium term ensures that we account properly for the convergence to the estimated long run stochastic balanced growth path when tracking the short-run dynamics. We represent the dynamic behavior of $\Delta \ln \left(A_{i, t}\right)$ and $\Delta \ln \left(R \& D_{i, t}\right)$ as follows:

$$
\begin{aligned}
\Delta \ln \left(A_{i, t}\right) & = \\
& =d_{1} \widehat{\epsilon}_{i t-1}+\sum_{z=1}^{2} \eta_{1 z} \Delta \ln \left(R \& D_{i, t-z}\right)+\sum_{z=1}^{2} \eta_{2 z} \Delta \ln \left(A_{i, t-z}\right)+\sum_{z=1}^{2} \eta_{3 z} \Delta \ln \left(A_{R O W i, t-z}\right)+e_{A i t} \\
\Delta \ln \left(R \& D_{i, t}\right) & = \\
& =d_{2} \widehat{\epsilon}_{i t-1}+\sum_{z=1}^{2} v_{1 z} \Delta \ln \left(R \& D_{i, t-z}\right)+\sum_{z=0}^{1} v_{2 z} \Delta \ln \left(A_{i, t-z}\right)+\sum_{z=0}^{1} v_{3 z} \Delta \ln \left(A_{R O W i, t-z}\right)+e_{R D i t}
\end{aligned}
$$

Equations (11) and (12) are sufficient to characterize the dynamics of the idea-generating system in the world, as the international stock of knowledge, $A_{R O W i, t}$, is simply given by the sum of $A_{j, t}$ for all countries other than $i$. The term $\hat{\epsilon_{i, t}}$ is the disequilibrium term and is equal to $\ln \left(A_{i t}\right)-\widehat{c}_{i}-$ $\widehat{\lambda_{i}} t-\widehat{\mu} \ln \left(R \& D_{i t}\right)-\widehat{\gamma} \ln \left(A_{R O W i, t}\right)$. We construct it using the cointegration relation estimated in the previous section. It represents the deviation from the equilibrium relationship and the coefficients 
$d_{1}$ and $d_{2}$ measure how the disequilibrium generates adjustment in order to preserve the long run equilibrium. The Granger representation theorem implies that at least one of the $d_{i}$ coefficients must be non-zero if a long run relationship between the variables is to hold. The estimates of $d_{1}$ and $d_{2}$ in our system are equal to -0.070 (s.e 0.020 ) and 0.022 (s.e.0.08) respectively. The first coefficient estimate is negative, significant and it guarantees that the system does actually converge to its stochastic long run relation. The second coefficient is positive but not statistically significant, implying that in the long run the variable $R \& D$ is weakly exogenous. Rather than presenting the estimates of the other dynamic coefficients, we show the impulse responses (IR) of knowledge and R\&D resources to $e_{A i t}$ and $e_{R D i t}$ respectively. These responses provide a description of the short and medium run effects of shocks.

\subsection{Impulse Response and Discussion}

Given our flexible specification that allows for country specific effects and spillover effects through the term $A_{R O W i, t}$ the impulse response of country $i$ to an innovation of one of the two equations in country $j$ could be different for each $i$ and $j$. However, due to the short dimensions of our panel we impose that the sets of coefficients $\eta_{1 z}, \eta_{2 z}, \eta_{3 z}$ and $v_{1 z}, v_{2 z}, v_{3 z}$ are equal across countries. The VECM identification (as one can see from equations 12 and 11) is Choleski-type with $\Delta \ln \left(A_{i, t}\right)$ ordered first and $\Delta \ln \left(R \& D_{i t}\right)$ ordered last. A shock to a country that provides a relevant contribution to the international stock of knowledge, $A_{R O W i, t}$, has, through this channel, a relevant impact on innovation and on the choice of $\mathrm{R} \& \mathrm{D}$ resources for all other countries. To the contrary an innovation shock to a country that contributes only minimally to $A_{R O W i, t}$ mainly affects its own innovation and R\&D only. In order to illustrate this comparison in its most extreme form, we choose to report the impulse response of $\ln \left(R \& D_{i, t}\right)$, and $\ln \left(A_{i, t}\right)$ for a representative country ${ }^{22}$, to shocks $e_{A j t}$ and $e_{R D j t}$ originating in the U.S. (the largest country in the sample) and in Ireland (the smallest country in the sample) ${ }^{23}$. Panels 1 through 4 present the complete set of estimated impulse response functions (along with the $99 \%$ confidence intervals) for each variable in the orig-

\footnotetext{
${ }^{22}$ Since we impose that the coefficients in the VAR are all equal among countries the IR functions are all similar. The representative country is obtained by averageing the impulse responses in all countries other than the one where the shock originates.

${ }^{23}$ Impulse response functions for single countries to the same shocks are available from the authors.
} 
inating country and the representative foreign country ${ }^{24}$. Panel 1 tracks the 23 year response in the US and in the representative foreign country to a shock to US innovation, $e_{A, U S t}$. Panel 2 does the same for a shock to US R\&D employment, $e_{R D, U S, t}$. Panel 3 tracks the effect of a shock to Ireland's innovation, $e_{A, I E t}$, and Panel 4 shows the effect of a shock to Ireland's R\&D employment, $e_{R D, I E, t}$. The remainder of this section describes each panel, in turn.

Figures 1.1 and 1.2 of Panel 1 represent the dynamic response of the US and representative country's stock of knowledge (denoted with an $r$ ) to a $1 \%(0.13)$ unexpected increase in US innovation at the beginning of the period. Both the US and country $r$ stocks of knowledge increase significantly during the first ten to thirteen years after the shock, and then revert to a smaller, still positive effect exhibiting an overall hump-shape. The impact of the US shock on the stock of knowledge of the representative foreign country $(r)$ reaches +0.02 at the end of the period considered, which corresponds to an increase of $0.17-0.30 \%$ of the average stock of its knowledge. This effect is due to two components. First, higher US knowledge increases the stock of world knowledge and this benefits innovation in all countries. Second, in the medium-long run, higher world knowledge drives higher investment in R\&D resources of both the US (figure 1.3) and of the representative country (figure 1.4), which in turn contributes to innovation. The effect of this shock on US innovation itself (fig.1.1) and on US R\&D employment (fig. 1.3) is large and builds up in the short run, reaching a peak after 5-10 years and declining afterwards. After twenty years the impact on the US stock of knowledge is roughly equal to 0.13 , which is a value close to the initial shock. Interestingly, these impulse responses reveal that both US and foreign R\&D employment react positively to an innovation shock in the US, and that such a reaction takes a long time to reach its peak (5-10 years). This implies that the strongest effect of the positive shock to innovation is felt in the US and international scientific community with a significant delay.

Panel 2 reports the dynamic effects of a shock to US R\&D employment on its stock of knowledge and subsequent R\&D employment, as well as on those of the representative country. As expected, it takes few periods for the $R \& D$ shock (represented in figure 2.3 as the initial jump of the variable) to build its full effect on the stock of knowledge generated in the US (figure 2.1). Moreover, the positive feedback of $R \& D$ employment to increases in knowledge (illustrated in panel 1) is also at work so

\footnotetext{
${ }^{24}$ The confidence intervals are calculated using the Monte Carlo method and the updating algorithm due to Jain and Chlamtac (1985) provided by Eviews 5.1. The algorithm provides a reasonable estimate of the tails of the underlying distribution when the number of repetitions is not too small.
} 
that $R \& D$ employment further increases after the initial positive shock. After 23 years, the increase in $\ln \left(A_{U S, t}\right)$ reaches a level equal to $0.6 \%(+0.08)$ of the average stock of US knowledge. The increase in $\ln \left(R \& D_{U S}\right)$ resources stabilizes earlier (after 10-12 years) at +0.25 , which represents a $1.9 \%$ increase over the average stock of knowledge in the sample. Consistent with the behavior shown in Panel 1, the impact of $e_{R D, U S, t}$ on the stock of knowledge of the representative foreign country is positive (an average increase of 0.18-0.35\% ) and is somewhat delayed (as shown in figure 2.3). Finally, the R\&D of the representative country responds positively and with a delay to the increased US R\&D employment (figure 2.4). Overall, the strongest effect of an increase in $R \& D$ employment on innovation takes place with a five to ten year lag. In the long run, an increase in the stock of world knowledge is consistent (due to the cointegration relation) with higher R\&D and higher stock of national knowledge for all countries.

Panels 3-4 show the impulse response of knowledge and R\&D resources to shocks taking place in Ireland, the smallest country in our sample (in terms of number of patents and R\&D employment). The general shape and timing of these impulse responses are similar to those of Panels 1 and 2. A notable difference exists, however. Given that the US is the major contributor to world knowledge, while Ireland is a marginal one, shocks to the Irish R\&D sector have quantitatively smaller effects on the innovation sector of the representative foreign country. The impulse response of Irish knowledge and $R \& D$ to its own shocks $\left(e_{A, I E t}, e_{R D, I E, t}\right)$, reported in Panels 3 and 4 , are similar to the own responses found for US variables to US shocks. The response of $\ln \left(A_{i t}\right)$ to $e_{A, I E t}$ (figure 3.1) is hump shaped with maximum effect after five years: the initial $1 \%$ increase in the stock of Irish knowledge is almost unchanged after twenty years. The increase in R\&D resources after the shock (portrayed in figure 3.3) is smaller (in absolute value) for the simple reason that the spillover effect generated by other countries' increased stock of knowledge and R\&D (reported respectively in figure 3.2 and 3.4 ) is now much smaller (notice the scale). Similar patterns emerge when we look at a response to the shock $e_{R \& D, I E t}$ (figures 4.1 and 4.3 ). IR's functions show a progressive increase and by the twentieth year they have reached a plateau. To the contrary, the responses of other countries to these shocks are very small and, even in the long run, typically less than a hundredth of a percentage point of the initial shock (as seen in figures 4.2 and 4.4). As the impact is so small, some nuisances (such as country effects or lagged effects) cause the IR's to have somewhat different shapes from those generated by US shocks on the representative 
foreign economy. Altogether, however, the external effect of a small country such as Ireland on the dynamics of other country's innovation and $R \& D$ is negligible both in the short and in the long run.

\section{Conclusions}

Positive shocks to the innovative activity of a country are the source of booms in the short run and of sustained productivity growth in the long run. Analyzing them in a coherent framework that tracks their consequences at different time horizons is a way of reconciling the short and the long run. Recent economic analysis has largely neglected such research. This paper takes a first step to fill the gap by analyzing one phase of the innovation process: namely, the interaction of $\mathrm{R} \& \mathrm{D}$ resources and technological knowledge in the generation of new ideas. We apply some recent methods to estimate the cointegration (long run) relationship between these variables. Moreover we use an error correction mechanism to estimate short and medium run responses. We find that, in the long run, internationally generated knowledge is an important contributor to the innovation of a country. The stock of knowledge of a country responds to international knowledge with elasticity between 0.2 and 0.5 . We then estimate the impulse dynamic response to an innovation shock in the short and medium run. A large country as the US would have a non-negligible impact on other countries' knowledge creation even in the short run. A $1 \%$ positive shock to the log of R\&D in US increases the knowledge creation in other countries by an average of $0.35 \%$ within ten years. The same shock generates a maximum $6 \%$ effect on the US stock of knowledge after five to ten years and then declines slightly. By analyzing the impact of a similar shock originating in a small country, however, we see that while the qualitative features of the impulse responses to innovation shocks are similar, the quantitative effects on knowledge creation of other countries are negligible. 


\section{References}

Aghion, P. and Howitt, P. (1992). 'A Model of Growth Through Creative Destruction,' Econometrica Vol. 60, pp. 323-51.

Banerjee, A. (1999). 'Panel Data Unit Roots and Cointegration: An Overview,' Oxford Bulletin of Economics and Statistics, Vol. 61, pp.607-629.

Barro, R. and Sala i Martin X. (2004). 'Economic Growth' MIT Press, Cambridge, Ma.

Branstetter, L. (2001). 'Are Knowledge Spillovers International or Intranational in Scope? Microeconometric Evidence from the U.S. and Japan,' Journal of International Economics, Vol. 53(1), pp. 53-79.

Caballero, R. and Jaffe, A. (1993). 'How High are the Giants' Shoulders: An Empirical Assessments of Knowledge Spillovers and Creative Destruction in a Model of Economic Growth,' NBER Macroeconomic Annuals, Vol. 8 pp.15-72, MIT Press, Cambridge MA.

Campbell, J. and Perron, P. (1991). 'Pitfalls and Opportunities: What Macroeconomists Should Know about Unit Roots,' in Olivier Jean Blanchard and Stanley Fischer, eds,. NBER Macroeconomics Annual 1991. Cambridge and London: MIT Press, pp. 141-201.

Coe, D. and Helpman, E. (1995). 'International R\&D Spillovers,' European Economic Review, Vol. 39, pp. 859-887.

Christiano, L. and Eichenbaum, M. (1992). 'Current Real Business Cycle Theories and Aggregate Labor Market Fluctuations,' American Economic Review, Vol. 82, pp. 430-450.

Eaton, J. and Kortum, S. (1996). 'Trade in Ideas: Patenting and Productivity in the OECD,' Journal of International Economics, Vol. 40, pp. 251-278.

Engle, R. and Granger, C. (1987). 'Co-integration and Error-Correction: Representation, Estimation, and Testing,' Econometrica, Vol. 55, pp. 251-76.

Edmond, C. (2001). 'Some Panel Cointegration Models of International R\&D Spillovers,' Journal of Macroeconomics, Vol. 23(2), pp. 241-60. 
Funk, M. (2000). 'Trade and International R\&D Spillovers among OECD Countries,' Southern Economic Journal, Vol. 67(3), pp. 725-36.

Griliches, Z. (1990). 'Patent Statistics as Economic Indicators: A Survey,' Journal of Economic Literature Vol. 28, pp. 1661-1707.

Griliches, Z. (1992). 'The Search for R\&D Spillovers,' Scandinavian Journal of Economics. Vol. 94(0), pp. 29-47.

Grossman, G. and Helpman, E.(1991). 'Innovation and Growth in the Global Economy,' The MIT Press, Cambridge, Ma.

Hall, B., Griliches, Z. and Hausman, J.A. (1986). 'Patents and R\&D: Is There a Lag?,' International Economic Review Vol. 27, pp. 265-283.

Hall, B., Jaffe, A. and Trajtenberg, M. (2005). 'Market Value and Patent Citations,' Rand Journal of Economics, Vol.36, pp.16-38.

Im, K.Y. Pesaran, H. and Shin, Y. (2003) 'Testing for Unit Roots in Heterogenous Panels,' Journal of Econometrics, Vol. 115, pp.53-74.

Jain, R. and Chlamtac, I. (1985). 'Dynamic Computation of Median and Percentiles', Communications of the ACM, Vol. 28, No. 10.

Jaffe, A. and Trajtenberg, M. (2002). 'Patents, Citations and Inovations, a Window on the Knowledge Economy' MIT Press, Cambridge, MA.

Jaffe, A., Trajtenberg, M. and Henderson, R. (1993) 'Geographic Localization of Knowledge Spillovers as Evidenced by Patent Citations' Quarterly Journal of Economics, Vol. 108, pp.57798.

Johansen, S. (1988). 'Statistical Analysis of Cointegrateing Vectors', Journal of Economic Dynamics and Control, Vol. 12, pp. 231-54.

Johansen, S. (1991). 'Estimation and Hypotehsis testing of Cointegration Vectors in Gaussian Vector Autoregressive Models', Econometrica, Vol. 6, pp. 1551-80 
Johansen, S. (1995).'Likelihood-Based Inference in Cointegrated Vector Autoregressive Models,' Oxford: Oxford University Press.

Jones, C. (1995). 'Time Series tests of Endogenous Growth Models" Quarterly Journal of Economics, Vol.110. pp.495-525.

Jones, C. (2002). 'Introduction to Economic Growth', New York, W.W. Northon and Company.

Jones, C. (2004) "Growth and Ideas" NBER Working Paper \#10767

Kao, C. (1999). 'Spurious Regression and Residual-Based tests for Cointegration in Panel Data' Journal of Econometrics, Vol. 90, pp. 1-44.

Kao, C. Chiang, M.H. and Chen, B. (1999). 'International R\&D Spillovers: and Application of Estimation and Inference in Panel Cointegration,' Oxford Bulletin of Economics and Statistics, Vol. 61, pp. 691-709.

Keller, W. (1998). 'Are International R\&D Spillovers Trade-Related? Analyzing Spillovers among randomly Matched Trade Partners,' European Economic Review, Vol. 42, pp. 1469-81.

Keller, W. (2002). 'Geographic Localization of International Technology Diffusion,' American Economic Review, Vol. 92, pp.120-142.

Kortum ,S. (1997). 'Research Patenting and Technological Change,' Econometrica, Vol. 65(6), pp.1389-1419.

Kydland, F. and Prescott, E. (1982). 'Time to Build and Aggregate Fluctuations,' Econometrica, Vol. 50, pp. 1345-1370.

Larsson, R., Lyhagen, V. and Othgren, M. L . (2001). 'Likelihood-based Cointegration Tests in Heterogeneous Panels,' Econometrics Journal, Vol. 4, pp. 109-142.

Mark, C.N., Ogaki, M. and Sul, D. (2003). 'Dynamic Seemingly Unrelated Cointegrating Regression,' NBER Working Paper \# t0292.

Pakes, A. and Griliches, Z. 'Patents and R\&D at the Firm Level: a First Report,' Economic Letters Vol. 5, pp. 377-81. 
Pedroni, P. (1995). 'Panel Cointegration; Asymptotic and Finite Sample Properties of Pooled Time Series Tests, With an Application to the PPP Hypothesis', Indiana University Working Papers In Economics No. 95-013.

Pedroni, P. (1999). 'Critical Values for Cointegration Tests in Heterogeneous Panels with Multiple Regressors,' Oxford Bulletin of Economics and Statistics, Vol. 61, pp. 653-70.

Pedroni, P. (2004). 'Panel Cointegration; Asymptotic and Finite Sample Properties of Pooled Time Series Tests with an Application to the Purchasing Power Parity Hypothesis,' Econometric Theory, Vol. 20, pp. 597-325.

Peri, G. (2005). 'Determinants of Knowledge Flows and their Effects on Innovation,' Review of Economics and Statistics, Vol. 87(2), pp. 308-322.

Pesaran, H. (2003) 'ASimple Panel Unit Root Test in the presence of Cross-Section dependence,' September 2003 (Revised January 2005), Cambridge University DAE Working Paper, No. 0346

Pesaran, M.H., Shin, Y. and Smith, R. (1999). 'Pooled Mean Group Estimation of Dynamic Heterogeneous Panels", Journal of the American Statistical Association, Vol.94, pp.621-634

Phillips, P. and Moon, H. (1999). 'Linear Regression Limit Theory for non-Stationary Panel Data,' Econometrica, Vol. 67, pp. 1057-1112.

Prescott, E. (1986) 'Theory Ahead of Business Cycle Measurement,' Carnegie-Rochester Conference Series on Public Policy Vol. 25, pp.11-44.

Ramsey, F.P. (1928). 'A Mathematical Theory of Saving' Economic Journal, Vol. 38, 543-559.

Romer, P.M., (1990). 'Endogenous Technological Change,' Journal of Political Economy, Vol. 98(5), pp.71-102.

Segerstrom, P.(1998). 'Endogenous Growth without Scale Effects,' American Economic Review, Vol. 80(5), pp.1077-1091.

Shea, J. (1999) 'What do Technology Shocks Do?' in Bernanke, B. and Rotemberg J., eds. NBER Macroeconomics Annual 1998. Vol. 13. Cambridge and London: MIT Press; pp. 275-310. 
Solow, R. (1956). 'A Contribution to the Theory of Economic Growth,' Quarterly Journal of Economics Vol. 70, pp. 65-94.

Solow, R. (1957). 'Technical Change and the Aggregate Production Function,' Review of Economics and Statistics, Vol. 39, pp. 312-20.

Weil, P. (2005). Economic Growth Pearson, Addison-Wesley, Boston, San Francisco, New York.

Young, A. (1995). 'The Tyranny of Numbers: Confronting the Statistical Realities of East Asian Growth Experiences' Quarterly Journal of Economics Vol. 110 (3), pp. 641-680. 


\section{Tables and Figures}

Table 1

Summary Statistics for R\&D, Patents and the constructed Stocks of Knowledge

\begin{tabular}{lclcc}
\hline Country & $\begin{array}{l}\text { Average R\&D } \\
\text { Personnel, Full- } \\
\text { time Equivalents }\end{array}$ & $\begin{array}{l}\text { Average } \\
\text { Number of } \\
\text { Patent } \\
\text { Applications } \\
\text { per year }\end{array}$ & $\begin{array}{l}\text { Average value } \\
\text { of } \begin{array}{l}\text { In(A), Stock } \\
\text { of domestically } \\
\text { generated } \\
\text { knowledge }\end{array}\end{array}$ & $\begin{array}{l}\text { Average value of } \\
\text { In(ARow), Stock of } \\
\text { International } \\
\text { knowledge }\end{array}$ \\
\hline Australia & & & & \\
Canada & 63390 & 551 & 8.18 & 13.66 \\
Germany & 103418 & 2245 & 9.64 & 13.65 \\
Denmark & 401850 & 8738 & 11.11 & 13.59 \\
Spain & 21871 & 253 & 7.49 & 13.66 \\
Finland & 53537 & 148 & 6.85 & 13.67 \\
France & 25369 & 326 & 7.39 & 13.67 \\
Great Britain & 271446 & 3559 & 10.16 & 13.64 \\
Ireland & 289102 & 3491 & 10.33 & 13.63 \\
Italy & 6774 & 57 & 5.69 & 13.67 \\
Japan & 120927 & 1339 & 9.13 & 13.66 \\
The Netherlands & 764375 & 23215 & 11.66 & 13.50 \\
Norway & 65264 & 1094 & 9.01 & 13.66 \\
Sweden & 18510 & 140 & 6.90 & 13.67 \\
USA & 49587 & 1073 & 9.06 & 13.66 \\
\hline
\end{tabular}

Notes: The averages are taken for each country over the years 1973-1999.

The variables $\ln (\mathrm{A})$ and $\ln \left(\mathrm{A}_{\mathrm{ROW}}\right)$ are constructed as described in the main text, by accumulating patents using the perpetual inventory method. 
Table 2

Tests of Unit Roots for R\&D and Stocks of Knowledge

\begin{tabular}{|c|c|c|c|c|c|c|}
\hline \multirow{2}{*}{$\begin{array}{c}\text { Test } \\
\text { Variable: }\end{array}$} & \multicolumn{3}{|c|}{ Im, Pesaran and Shin (2003) } & \multicolumn{3}{|c|}{ Pesaran (2003) } \\
\hline & $\ln (\mathrm{A})$ & $\ln \left(\mathrm{A}_{\mathrm{ROW}}\right)$ & $\ln (\mathrm{R} \& \mathrm{D})$ & $\ln (\mathrm{A})$ & $\ln \left(\mathrm{A}_{\mathrm{ROW}}\right)$ & $\ln (\mathrm{R} \& \mathrm{D})$ \\
\hline $\begin{array}{l}\text { Australia } \\
\text { Canada } \\
\text { Germany } \\
\text { Denmark } \\
\text { Spain } \\
\text { Finland } \\
\text { France } \\
\text { UK } \\
\text { Ireland } \\
\text { Italy } \\
\text { Japan } \\
\text { Nether. } \\
\text { Norway } \\
\text { Sweden } \\
\text { USA }\end{array}$ & $\begin{array}{l}-2.709 \\
-0.096 \\
-1.531 \\
-0.527 \\
-0.309 \\
-2.480 \\
-0.873 \\
-1.355 \\
-1.512 \\
-1.983 \\
-1.403 \\
-1.858 \\
-1.711 \\
-0.897 \\
0.293 \\
\end{array}$ & $\begin{array}{l}-0.768 \\
-0.792 \\
-0.590 \\
-0.780 \\
-0.781 \\
-0.778 \\
-0.777 \\
-0.773 \\
-0.779 \\
-0.755 \\
-0.125 \\
-0.767 \\
-0.778 \\
-0.773 \\
-1.546 \\
\end{array}$ & $\begin{array}{c}-0.338 \\
-1.370 \\
-1.314 \\
0.015 \\
-0.252 \\
0.760 \\
-1.577 \\
-0.711 \\
0.481 \\
-1.919 \\
-1.098 \\
0.813 \\
-1.035 \\
-0.611 \\
-1.655 \\
\end{array}$ & $\begin{array}{c}-0.294 \\
0.816 \\
-0.199 \\
-1.787 \\
0.502 \\
-0.871 \\
-1.915 \\
0.009 \\
-2.775 \\
-1.760 \\
1.902 \\
0.408 \\
-3.942 \\
-2.115 \\
-0.332 \\
\end{array}$ & $\begin{array}{c}-0.200 \\
-0.108 \\
-1.098 \\
-0.268 \\
-0.214 \\
-0.151 \\
-0.761 \\
-1.084 \\
-0.182 \\
-0.188 \\
6.396 \\
-0.242 \\
-0.258 \\
-0.629 \\
1.856 \\
\end{array}$ & $\begin{array}{l}-4.060 \\
-1.661 \\
-2.604 \\
-1.572 \\
-2.004 \\
-0.502 \\
-0.379 \\
-2.101 \\
0.441 \\
-2.083 \\
-0.349 \\
-2.268 \\
-1.885 \\
-1.580 \\
-0.521 \\
\end{array}$ \\
\hline $\begin{array}{c}\text { Average } \\
\text { ADF }\end{array}$ & -1.269 & $-0,770$ & $-0,654$ & & & \\
\hline $\begin{array}{c}\text { Test } \\
\text { Statistic }\end{array}$ & 4.117 & 6.404 & 6.939 & & & \\
\hline $\begin{array}{l}\text { Average } \\
\text { CADF }\end{array}$ & & & & -0.823 & 0.191 & -1.550 \\
\hline
\end{tabular}

Notes: The test statistics are distributed as $\mathrm{N}(0,1)$ under the null hypothesis of non-stationarity. The statistics in the first three columns are constructed using small sample adjustment factors from Im, Pesaran, and Shin (2003). Test statistics in column three to six follow the method described in Pesaran (2003).

The symbols $*, * *, * * *$ denote rejection of the null hypothesis of non-stationariety (against the alternative of stationarity) at the $10 \%, 5 \%, 1 \%$ significance levels. 
Table 3

Tests of Unit Roots for the Growth Rates of R\&D and Stocks of Knowledge

\begin{tabular}{|c|c|c|c|c|c|c|}
\hline Test & \multicolumn{3}{|c|}{ Im, Pesaran and Shin (2003) } & \multicolumn{3}{|c|}{ Pesaran (2003) } \\
\hline Variable & $\Delta \ln (\mathrm{A})$ & $\Delta \ln \left(\mathrm{A}_{\mathrm{ROW}}\right)$ & $\Delta \ln (R \& D)$ & $\Delta \ln (\mathrm{A})$ & $\Delta \ln \left(\mathrm{A}_{\mathrm{ROW}}\right)$ & $\Delta \ln (\mathrm{R} \& \mathrm{D})$ \\
\hline $\begin{array}{l}\text { Australia } \\
\text { Canada } \\
\text { Germany } \\
\text { Denmark } \\
\text { Spain } \\
\text { Finland } \\
\text { France } \\
\text { UK } \\
\text { Ireland } \\
\text { Italy } \\
\text { Japan } \\
\text { Nether. } \\
\text { Norway } \\
\text { Sweden } \\
\text { USA }\end{array}$ & $\begin{array}{l}-2.647 \\
-2.008 \\
-2.284 \\
-3.783 \\
-2.702 \\
-2.611 \\
-3.032 \\
-2.777 \\
-2.042 \\
-2.354 \\
-1.860 \\
-2.016 \\
-2.910 \\
-3.119 \\
-3.425 \\
\end{array}$ & $\begin{array}{l}-3.623 \\
-3.651 \\
-3.595 \\
-3.625 \\
-3.627 \\
-3.628 \\
-3.608 \\
-3.611 \\
-3.624 \\
-3.642 \\
-4.128 \\
-3.626 \\
-3.624 \\
-3.579 \\
-1.433 \\
\end{array}$ & $\begin{array}{l}-2.824 \\
-3.222 \\
-3.411 \\
-3.723 \\
-3.050 \\
-1.150 \\
-2.702 \\
-2.933 \\
-2.626 \\
-2.986 \\
-2.191 \\
-4.440 \\
-3.563 \\
-3.677 \\
-1.968 \\
\end{array}$ & $\begin{array}{r}-5.016 \\
-2.744 \\
-1.213 \\
-6.824 \\
-5.227 \\
-3.643 \\
-1.020 \\
-1.240 \\
-6.637 \\
-2.367 \\
-1.607 \\
-1.427 \\
-3.646 \\
-2.528 \\
-3.368 \\
\end{array}$ & $\begin{array}{c}-2.522 \\
-4.257 \\
-2.634 \\
-3.449 \\
-2.714 \\
-2.714 \\
-4.422 \\
-4.325 \\
-2.538 \\
-3.167 \\
0.635 \\
-2.514 \\
-3.035 \\
-6.524 \\
-1.281 \\
\end{array}$ & $\begin{array}{r}-2.640 \\
-4.586 \\
-4.864 \\
-4.482 \\
-4.191 \\
-2.376 \\
-3.684 \\
-6.359 \\
-3.527 \\
-5.318 \\
-3.367 \\
-5.452 \\
-3.790 \\
-2.614 \\
-5.729 \\
\end{array}$ \\
\hline $\begin{array}{c}\text { Average } \\
\text { ADF }\end{array}$ & $-2,638$ & $-3,508$ & $-2,964$ & & & \\
\hline $\begin{array}{c}\text { Test } \\
\text { Statistic }\end{array}$ & $-2,160 * * *$ & $-6,152 * * *$ & $-3,657 * * *$ & & & \\
\hline $\begin{array}{c}\text { Average } \\
\text { CADF }\end{array}$ & & & & $-3.234 * * *$ & $-3.044 * * *$ & $-4.198 * * *$ \\
\hline
\end{tabular}

Notes: The test statistics are distributed as $\mathrm{N}(0,1)$ under the null hypothesis of non-stationarity. The statistics in the first three columns are constructed using small sample adjustment factors from Im, Pesaran, and Shin (2003). Test statistics in column three to six follow the method described in Pesaran (2003).

The symbols *, **, *** denote rejection of the null hypothesis of non-stationariety (against the alternative of stationarity) at the $10 \%, 5 \%, 1 \%$ significance levels. 
Table 4

Estimates of the Long-Run Cointegration Relation

\begin{tabular}{|c|c|c|c|c|c|c|c|}
\hline $\begin{array}{l}\text { Dependent } \\
\text { Variable: } \\
\text { Ln(A) }\end{array}$ & $\begin{array}{l}\text { I: } \\
\text { Basic }\end{array}$ & $\begin{array}{l}\text { II: } \\
\text { Allowing } \\
\text { Heterogeneous } \\
\text { Time Trends }\end{array}$ & $\begin{array}{l}\text { III: } \\
\text { Using Un- } \\
\text { weighted } \\
\text { Patents to } \\
\text { Construct A }\end{array}$ & $\begin{array}{l}\text { IV: } \\
\text { Allowing } \\
\text { Year } \\
\text { Effects }\end{array}$ & $\begin{array}{l}\text { V: } \\
\text { Omitting } \\
\text { the U.S. }\end{array}$ & $\begin{array}{l}\text { VI: } \\
\text { Splitting } \\
\text { Non-G7 } \\
\text { (a) }\end{array}$ & $\begin{array}{l}\text { Sample } \\
\text { G7 } \\
\text { (b) }\end{array}$ \\
\hline $\operatorname{Ln}(\mathbf{R} \& D)$ & $\begin{array}{c}0.786 * * * \\
(12.075)\end{array}$ & $\begin{array}{r}0.304 * * * \\
(4.671)\end{array}$ & $\begin{array}{l}0.317 * * * \\
(6.46)\end{array}$ & $\begin{array}{l}0.746 * * * \\
(11.162)\end{array}$ & $\begin{array}{l}0.401 * * * \\
(5.98)\end{array}$ & $\begin{array}{l}0.030 \\
(0.379)\end{array}$ & $\begin{array}{r}0.699 * * * \\
(6.498)\end{array}$ \\
\hline $\operatorname{Ln}\left(\mathbf{A}_{\text {ROW }}\right)$ & $\begin{array}{r}0.557 * * * \\
(9.319) \\
\end{array}$ & $\begin{array}{r}0.168 * * \\
(1.719) \\
\end{array}$ & $\begin{array}{l}0.385 * * * \\
(6.525) \\
\end{array}$ & $\begin{array}{r}0.276^{* * *} \\
(3.004) \\
\end{array}$ & $\begin{array}{l}0.366 * * * \\
(3.388) \\
\end{array}$ & $\begin{array}{l}0.749 * * * \\
(4.989)\end{array}$ & $\begin{array}{r}-0.300 * * * \\
(-2.280) \\
\end{array}$ \\
\hline $\begin{array}{l}\text { Country Fixed } \\
\text { Effects }\end{array}$ & Yes & Yes & Yes & Yes & Yes & Yes & Yes \\
\hline $\begin{array}{l}\text { Country- } \\
\text { Specific }\end{array}$ & No & Yes & Yes & No & Yes & Yes & Yes \\
\hline $\begin{array}{l}\text { Time Trends } \\
\text { Time Fixed } \\
\text { Effects }\end{array}$ & No & No & No & Yes & No & No & No \\
\hline N.Obs & 390 & 390 & 390 & 390 & 364 & 208 & 182 \\
\hline
\end{tabular}

Note: Panel Data using 15 countries for the period 1972-1999.

Method of Estimation: Dynamic Ordinary Least Squares (DOLS)

Variance-covariance matrix of the coefficients is estimated using the dynamic panel variance estimator proposed by Mark et al. (2003).

t- statistics in parenthesis. $*, * *, * * *=$ significant at the 10,5 and $1 \%$ level.

Dependent variable: $\log$ of $\mathrm{A}$, the stock of accumulated patents invented by residents of the country. The patents considered are those registered at the U.S. patent office. Each patent is weighted by the average number of yearly citations during the first three years (except in specification III). The construction of A is described in detail in the main text. 
Table 5

Tests of Cointegration

\begin{tabular}{cc}
\hline Pedroni (1995) Test & \\
\hline PC2 & $-5.76^{* * *}$ \\
PC1 & $-5.03^{* * *}$ \\
\hline Pedroni (1999) Test & \\
\hline Panel v-statistic & 2.687 \\
Panel Ro-statistic & $-1.926^{* *}$ \\
Panel t-statistic & $-4.051^{* * *}$ \\
Group Ro-statistics & 0.487 \\
Group t-statistics & $-2.628^{* * *}$ \\
Panel t-statistic (parametric) & $-3.056^{* * *}$ \\
Group t-statistic (parametric) & $-4.221^{* * *}$ \\
\hline
\end{tabular}

***: reject the null hypothesis of no effect or no cointegration at $1 \%$ significance level, $* *$ at $5 \%$ significance level, * at $10 \%$ significance level 
Table 6

Rank-Test on the Number of Cointegration Relationships

\begin{tabular}{|c|c|c|c|c|c|}
\hline Country & Lag (Ki) & $\mathbf{r}=\mathbf{0}$ & $\mathbf{r}=\mathbf{1}$ & $\mathbf{r}=\mathbf{2}$ & Rank (ri) \\
\hline Australia & 1 & 80.90 & 27.00 & 9.53 & 3 \\
\hline Canada & 1 & 12.32 & 6.06 & 2.74 & 0 \\
\hline Germany & 1 & 78.66 & 14.39 & 1.79 & 1 \\
\hline Denmark & 1 & 22.56 & 5.15 & 0.00 & 0 \\
\hline Spain & 1 & 24.91 & 7.30 & 0.17 & 1 \\
\hline Finland & 1 & 37.01 & 4.05 & 1.53 & 1 \\
\hline France & 1 & 60.62 & 14.42 & 3.97 & 1 \\
\hline Great Britain & 1 & 42.95 & 11.71 & 2.77 & 1 \\
\hline Ireland & 1 & 51.63 & 17.72 & 2.23 & 1 \\
\hline Italy & 1 & 64.23 & 18.22 & 3.34 & 1 \\
\hline Japan & 1 & 92.21 & 10.18 & 1.78 & 1 \\
\hline Netherlands & 1 & 70.79 & 16.01 & 2.39 & 1 \\
\hline Norway & 1 & 42.64 & 6.27 & 0.33 & 1 \\
\hline Sweden & 1 & 40.33 & 4.60 & 0.30 & 1 \\
\hline Usa & 1 & 75.39 & 5.33 & 1.39 & 1 \\
\hline Panel Tests & & $\mathbf{r}=\mathbf{0}$ & $\mathbf{r}=\mathbf{1}$ & $\mathbf{r}=\mathbf{2}$ & \\
\hline$\gamma_{L R}\left(H_{(r)} / H_{(3)}\right)$ & & 30.19 & 1.40 & 0.68 & \\
\hline
\end{tabular}

Empirical results of the trace test . All tests are performed at the 1\% level. For the country-by country tests the critical values are $24.08,12.21$, and 4.14 for testing $r=0,1$, and 2 respectively. The panel rank test has a critical value 1.645 .

The test follows Larsson et al. (2001). 
Figure 1

R\&D personnel in the $G 7$ countries, In(R\&D)

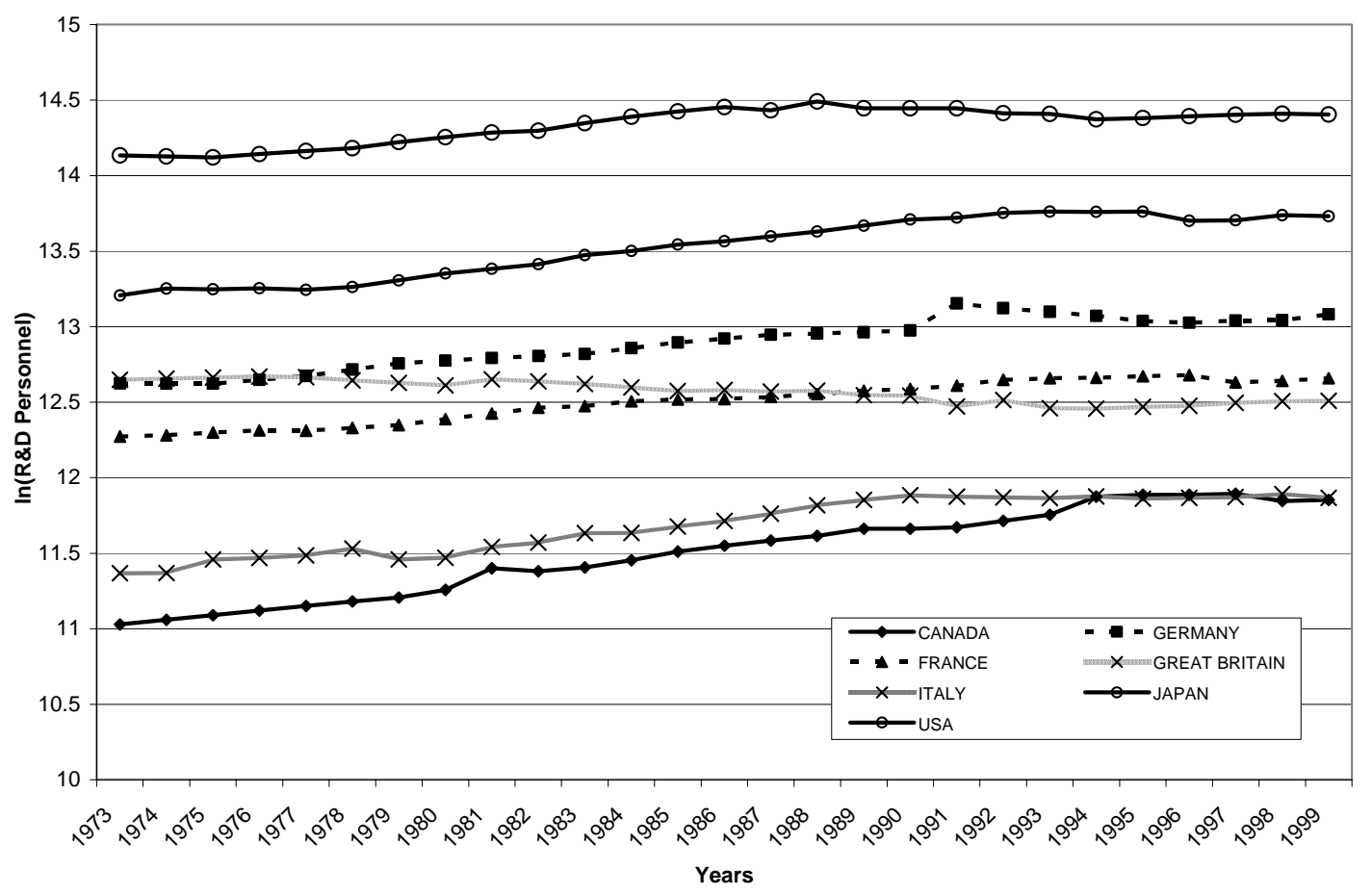

Figure 2

Annual Patent Applications in the G7 countries, In(Pat)

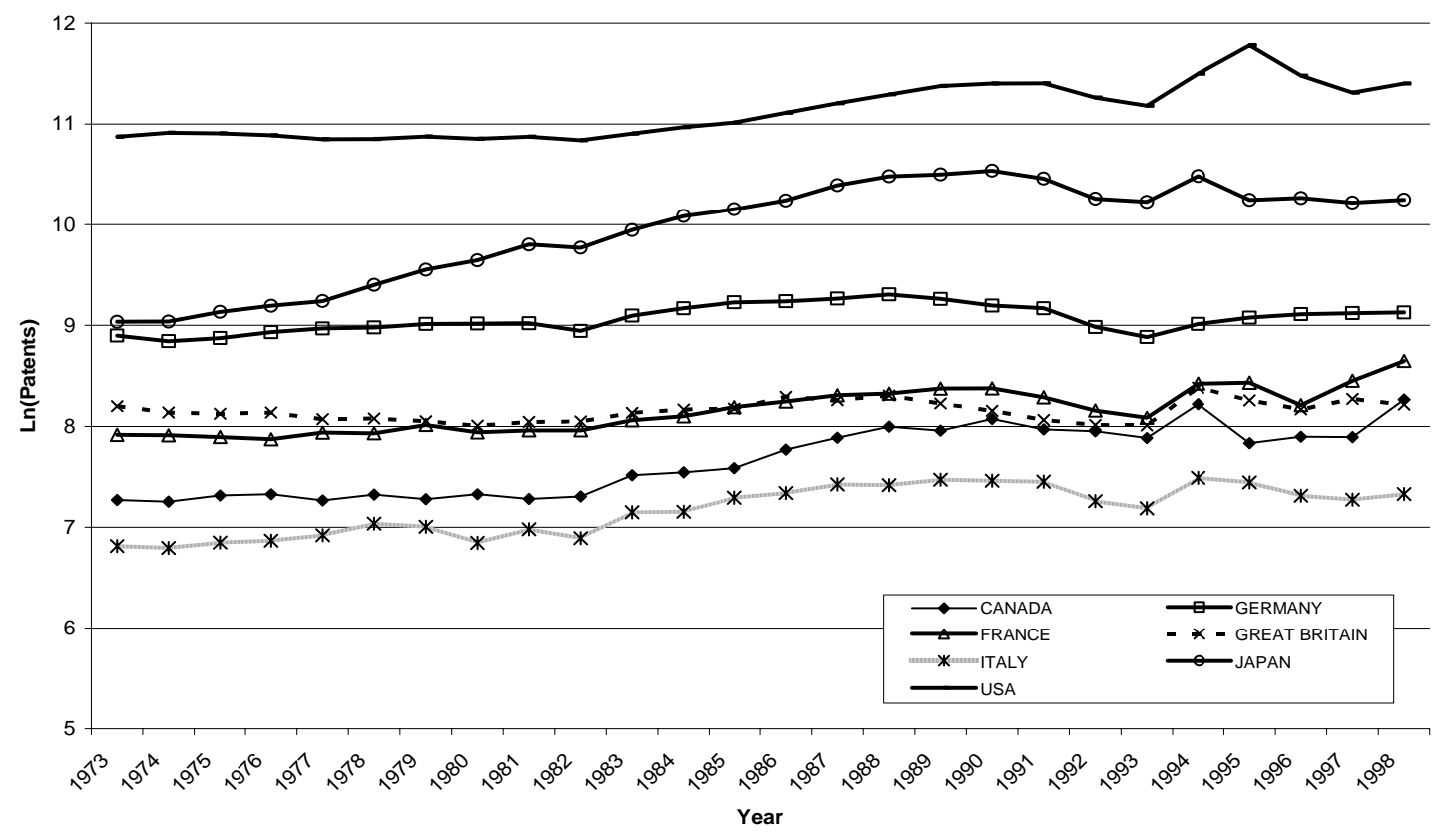

41 


\section{Figure 3}

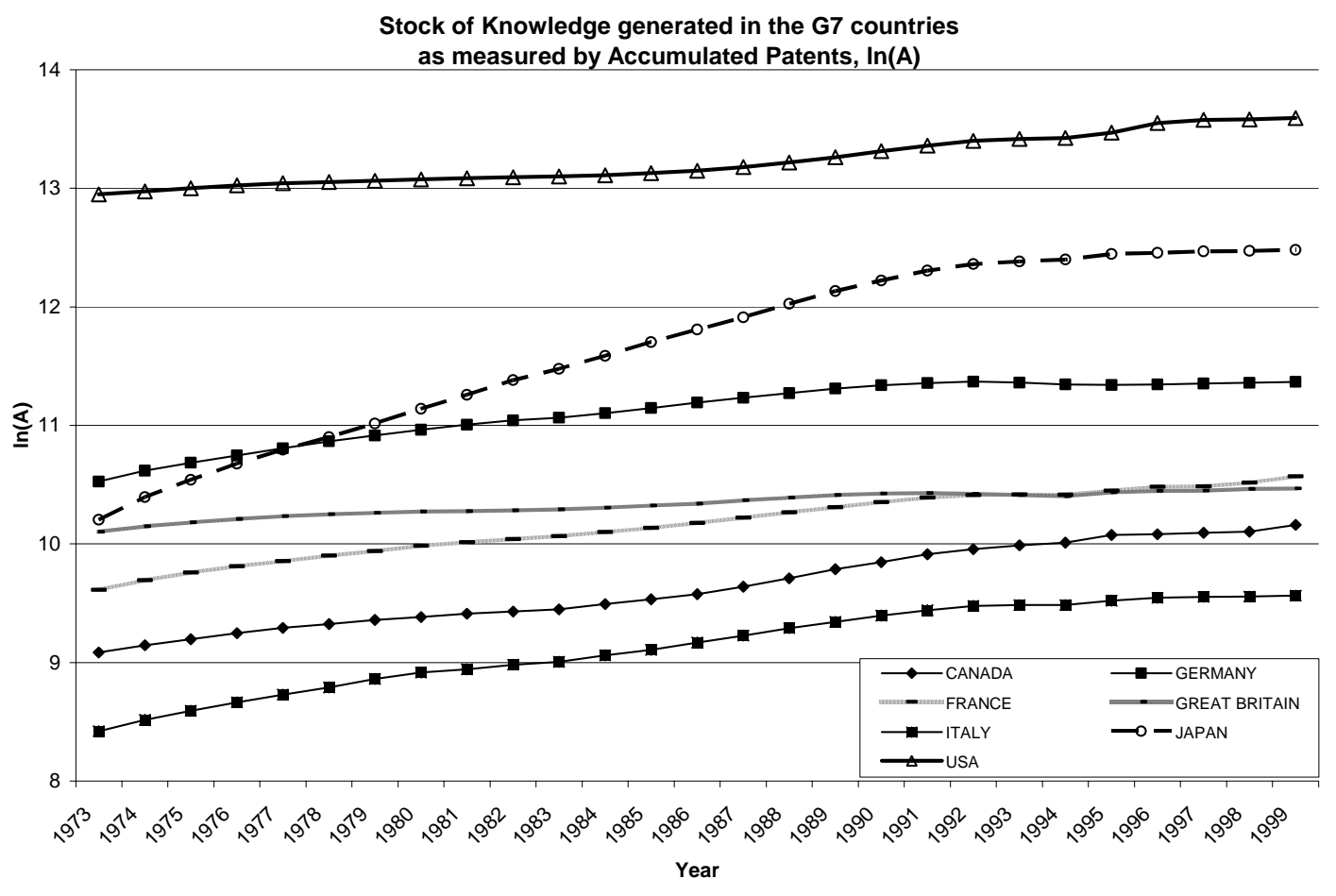


Panel 1: IR to $\varepsilon_{\mathrm{A}, \mathrm{US}, \mathrm{t}}$ (Shock to Innovation in the US)

1.1: $\ln \left(A_{U S}\right)$

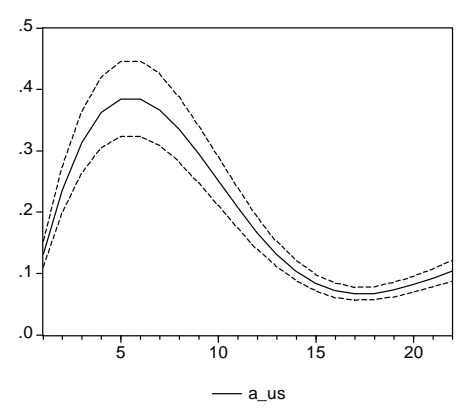

1.3: $\ln \left(R \& D_{U S}\right)$

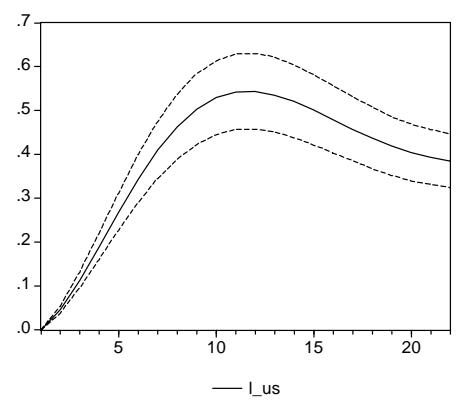

1.2: $\ln \left(A_{r}\right)$

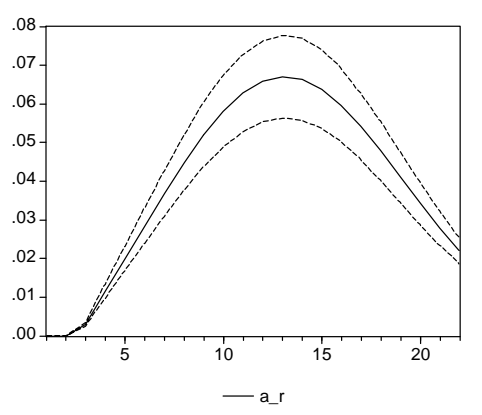

1.4: $\ln \left(R \& D_{r}\right)$

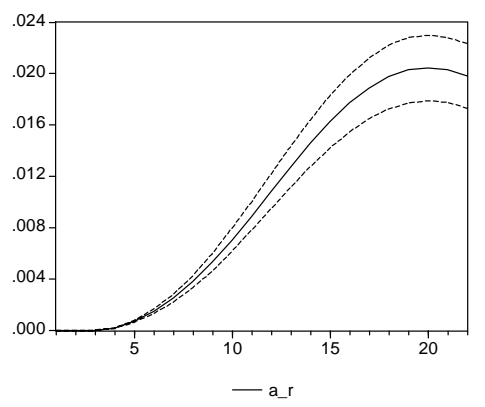

Panel 2: IR to $\varepsilon_{R \& D, U S, t}$ (Shock to R\&D Employment in the US)

2.1: $: \ln \left(A_{U S}\right)$

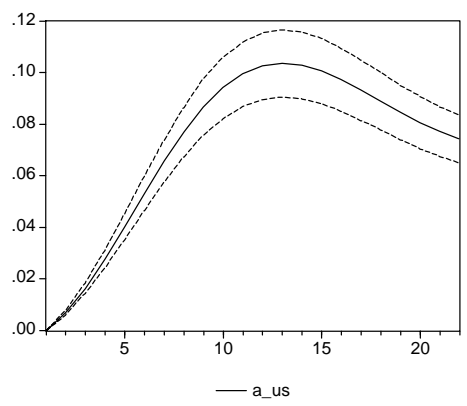

2.3: $\ln \left(R \& D_{U S}\right)$

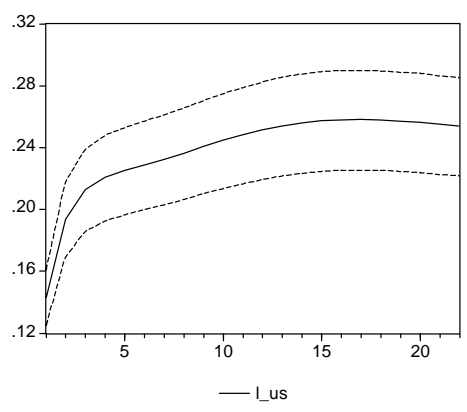

2.2: $\ln \left(A_{r}\right)$

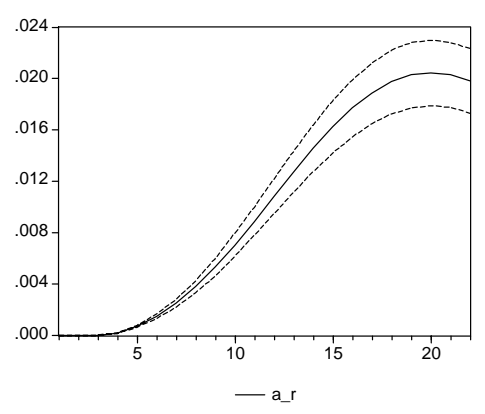

2.4: $\ln \left(R \& D_{r}\right)$

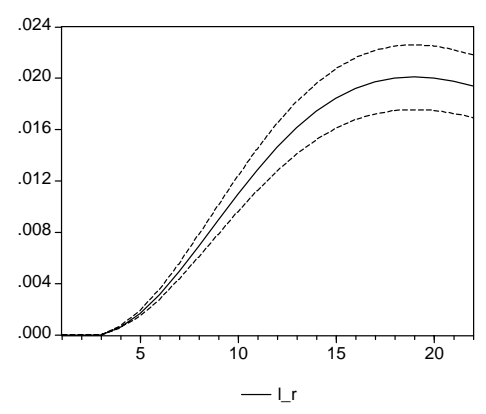


Panel 3: IR to $\varepsilon_{\mathrm{A}, \mathrm{IE}, \mathrm{t}}$ (Shock to Innovation in Ireland)

3.1: $\ln \left(\mathrm{A}_{\mathrm{IE}}\right)$

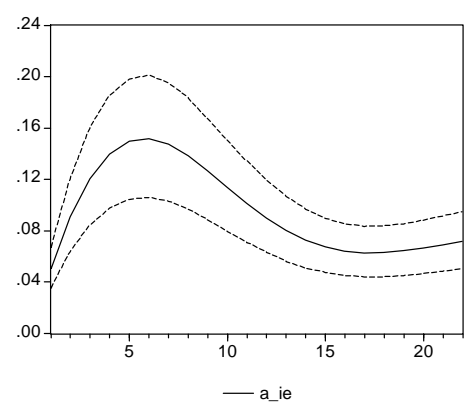

3.3: $\ln \left(R \& D_{\text {IE }}\right)$

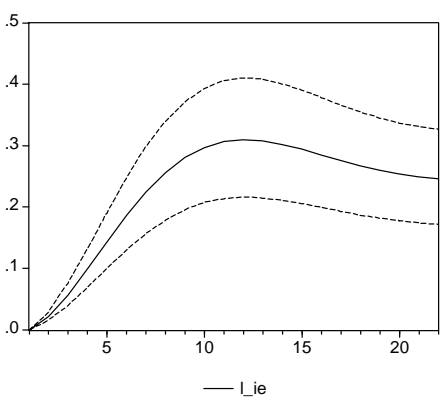

3.2: $\ln \left(A_{r}\right)$

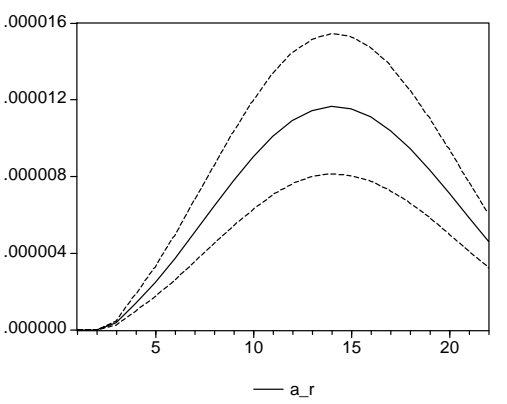

3.4: $\ln \left(R \& D_{r}\right)$

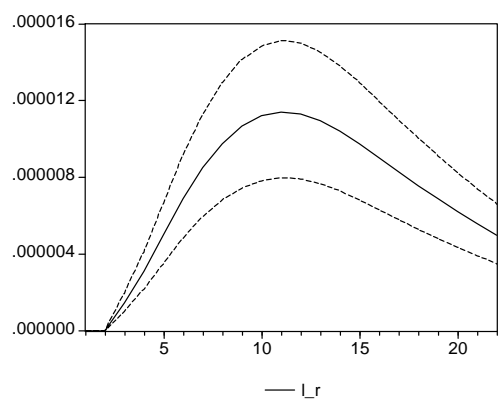

Panel 4: IR to $\varepsilon_{R \& D, I E, t}$ (Shock to R\&D Employment in Ireland)

4.1: $\ln \left(A_{I E}\right)$

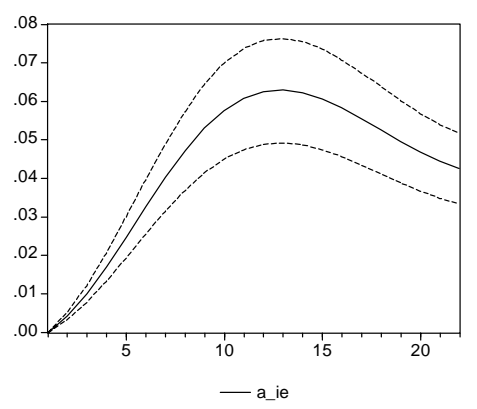

4.3: : $\ln \left(\mathrm{R} \& \mathrm{D}_{\mathrm{IE}}\right)$

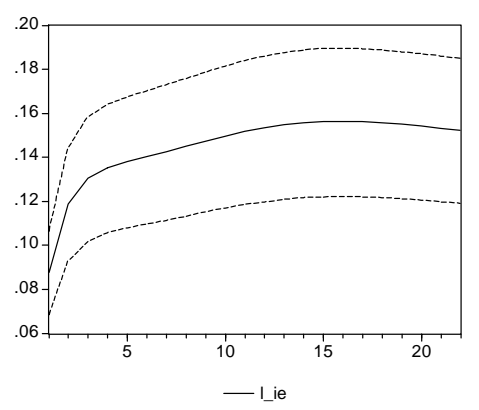

4.2: $\ln \left(A_{r}\right)$

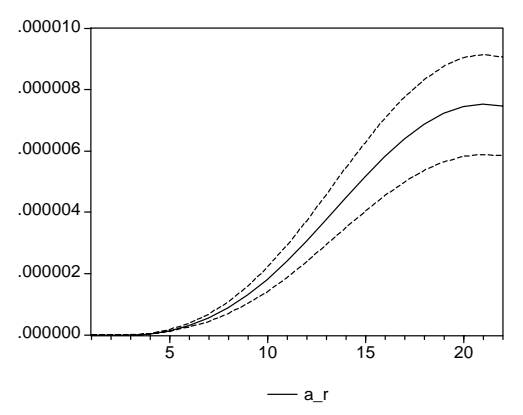

4.4: $\ln \left(R \& D_{r}\right)$

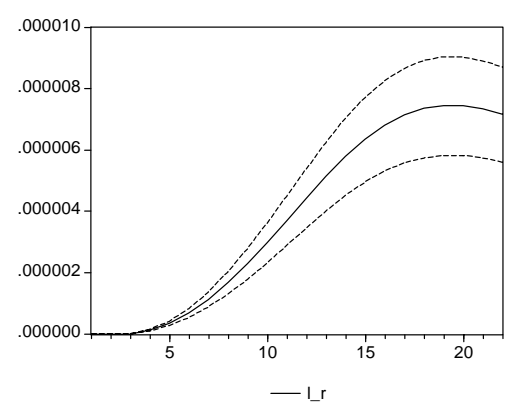

